
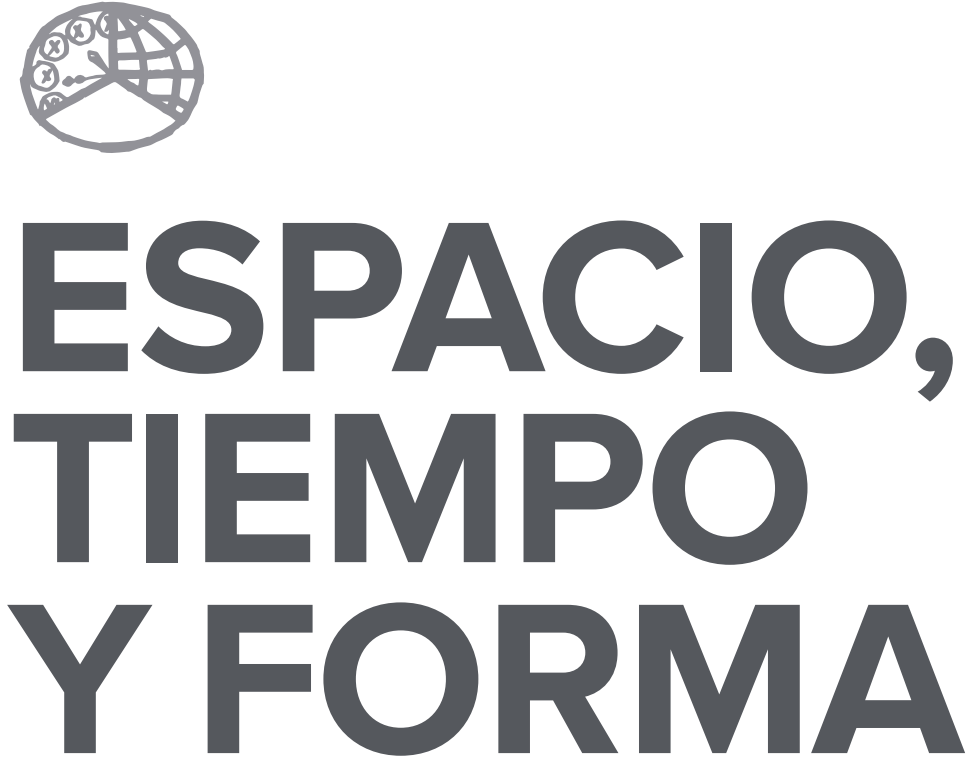

AÑO 2019

ISSN 0214-9745

E-ISSN 2340-1362

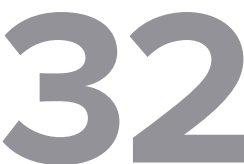

SERIE III HISTORIA MEDIEVAL

REVISTA DE LA FACULTAD DE GEOGRAFÍA E HISTORIA 



\section{ARTÍCULOS · ARTICLES}





\title{
UNA DEHESA POR DENTRO: CASTILRUBIO (1290-C. 1545). PAISAJE, EXPLOTACIÓN Y USURPACIÓN DE TÉRMINOS
}

\section{INSIDE A PASTURELAND: CASTILRUBIO (1290-C.1545). LANDSCAPE, MANAGEMENT AND ILEGAL APPROPRIATION}

\author{
Julián Clemente Ramos ${ }^{1}$
}

Recepción: 2018/06/25 - Comunicación de observaciones de evaluadores: 2018/11/05 . Aceptación: 2018/11/15

DOI: http://dx.doi.org/10.5944/etfiii.32.2019.22235

\section{Resumen}

Castilrubio es una dehesa situada en el SW del término de Medellín. Hemos seguido su evolución a través fundamentalmente de unas ricas fuentes procesales que nos han permitido integrar toda la problemática relacionada con el mundo rural y las estructuras de poder. Hasta mediados del siglo XV se encuentra rodeada de una densa vegetación. El proceso de roturación, en un contexto de crecimiento agrario y conflictividad política, va a desencadenar un proceso de usurpación que refrenda posteriormente la justicia real. Se documenta una explotación a pasto y labor a mediados del $\mathrm{XV}$, sustituida posteriormente en un contexto de subida de las hierbas por un aprovechamiento prioritariamente ganadero. En calidad de propietarios y luego de arrendatarios, labradores y élites rurales tienen un importante protagonismo.

\section{Palabras clave}

Dehesas; usurpaciones; paisaje rural; economía rural; baja Edad Media; siglo XVl. 


\begin{abstract}
Castilrubio is a pastureland located south-west of Medellin (Extremadura). We have detailed its evolution essentially using rich judicial records that have allowed us to combine issues regarding rural society with power structures. Until the middle of the fifteenth century these lands were surrounded by dense vegetation. The process of clearing the land in a context of agricultural growth and political conflict will trigger a phenomenon whereby land will be illegally appropriated, but eventually legalized by royal authority. This land was used for agriculture and livestock by the mid fifteenth century, but later exclusively used for livestock grazing in the context of the rise in the price of pasture. Farmers and rural elites play an important role first as owners and then as tenants of this property.
\end{abstract}

\title{
Keywords
}

Pasturelands; Illegal Appropriation; Countryside; Rural Economy; Later Middle Ages; Sixteenth Century. 


\section{INTRODUCCIÓN}

El presente estudio se centra en una dehesa de la tierra de Medellín (Castilrubio) con una capacidad estimada de ciento cincuenta vacas de hierba. Desconocemos la existencia de cualquier otro estudio similar para el periodo que estudiamos ${ }^{2}$. La disponibilidad de varios pleitos sobre esta dehesa y la información que hemos podido recabar sobre sus propietarios permiten insertar su estudio dentro de las líneas fundamentales del mundo rural castellano en la baja Edad Media. Por ello, el presente estudio supone una aproximación a estas grandes líneas a partir del análisis detallado y preciso de una pequeña unidad económica.

Las fuentes procesales, insuficientemente explotadas, pueden llegar a presentar una indudable riqueza. Aunque de modo general sólo estén disponibles desde finales del siglo XV, su información suele retrotraerse al menos una o dos generaciones, a veces más. En ocasiones anteriores, nos han permitido distintas aproximaciones con un importante componente cuantitativo. Su rica información se centra sobre personas o espacios muy circunscritos, lo que las hace muy adecuadas para estudios microhistóricos. Estos trabajos se han revelado como una herramienta de gran utilidad. Sin duda, no son útiles sin una perspectiva general. La abundante información disponible debe integrarse de forma adecuada en una perspectiva local y general para que nos permita una mejor compresión de las temáticas analizadas.

\section{PAISAJE, PROPIEDAD Y OCUPACIÓN DEL ESPACIO (1290-C. 1400)}

La primera mención documental de la dehesa de Castilrubio es relativamente temprana. Sancho IV la cede en I29o a Pedro Sánchez de la Cámara, «nuestro escribano», en compensación por la del Encinar, que le había donado previamente pero que la entregó finalmente al concejo de Medellín³. El nombre y la ubicación permiten pensar en una antigua fortaleza islámica ${ }^{4}$. Esta dehesa está situada en los límites con Zalamea, en el S/SW de la jurisdicción medellinense. El carácter periférico cobra un relieve especial si consideramos que estamos en una zona que presenta relieves residuales y moderadas pendientes. La ocupación del territorio

2. El trabajo sobre la dehesa de Miguel Muñoz abarca el siglo XIX (GARCíA SANZ, Ángel: «Explotación y renta en una dehesa salmantina durante el siglo XIX: Miguel Muñoz, 1802-1895», en CABERo DiÉGUEZ, Valentín (ed.): El medio rural español. Cultura, paisaje y naturaleza. Homenaje a don Angel Cabo Alonsamgo, vol. 1, Salamanca, Universidad de Salamanca, 1994, pp. 347-380).

3. SÁnCHEZ Loro, Domingo: Historias placentinas inéditas, vol. II, Cáceres, I. C. El Brocense, 1983, p. 80.

4. Se mantiene la memoria a finales del siglo XV de la antigüedad del castillo: «se llama [dehesa de] Castilruvio porquesta alli un castillo antiguo que se llamava Castilruvio» (Archivo de la Chancillería de Granada [AChG], c. 14529, $n^{\circ} 7$, f. 64v; igualmente, ff. 74 r ó 93v). 
en el término de Medellín fue selectiva y el espacio situado por encima de los 300 metros fue refractario a la ocupación en las décadas que siguieron a la conquista cristiana. Al sur del término, Manchita es la única aldea que se sitúa por encima de la cota de los 300 metros. Las únicas dehesas apropiadas fueron Castilrubio, Valdegamas y Zafrilla. Es posible que esta escasa ocupación en la zona S/SW de la jurisdicción supusiera un cambio profundo sobre la realidad previa a la ocupación hispanocristiana. No es improbable que los dos castillos documentados hayan estado relacionados con alquerías andalusíes. Medellín se presenta como un hisn densamente poblado y, sin duda, esta realidad debemos vincularla a su entorno territorials.

Esta escasa ocupación ha creado un paisaje muy particular. Sólo lo conocemos tardíamente. A principios del siglo XV debía estar completamente consolidado. El territorio S/SW del término albergó las mayores masas forestales de la jurisdicción y prácticamente la totalidad de las formaciones vegetales densas y cerradas ${ }^{6}$. La existencia de este paisaje no ofrece duda. En el deslinde de finales I290, se alude a las «losas de Juan Ferrus» y a la Jara ${ }^{7}$, lo que denota un espacio de abundante vegetación natural, no exenta de aprovechamiento como denota el dominio de una vegetación degradada, y caza. Los colmenares que se ubican, de modo preferente, en espacios con una rica y densa vegetación natural son un claro indicador paisajístico. En el siglo XV, en los límites de Castilrubio se mencionan los de Vicente García, las Merchanas, el Conejo, María Gómez y Juan Marcha (mapa 2). Es llamativo que estos colmenares rodeen literalmente Castilrubio, situándose próximos a las dehesas de Zafrilla o Valdegamas o a la tierra de Zalamea.

Las formaciones vegetales compactas y la riqueza faunística, percibida como nociva para la ocupación humana del territorio, forman una unidad indisoluble ${ }^{8}$. La actividad humana no ha afectado a las formaciones vegetales hasta mediados del siglo XV. Aún en el siglo XVI, después de un siglo de rozas y crecimiento agrario, el terreno que rodea a Castilrubio tiene una importante riqueza forestal. En un caso se citan, de modo especifico, «montes bravos xarales e carnecas e enzinales».

5. Clemente Ramos, Julián: La tierra de Medellín (1234-c. 1450): Dehesas, ganadería y oligarquía, Badajoz, Diputación de Badajoz, 2007, pp. 25-68.

6. Clemente Ramos, Julián: «El espacio pecuario en Medellín (1450-1550)», Anuario de Estudios Medievales, 43/2 (2013), p. 541. Juan Garcia de la Haba dirá para un periodo muy posterior sobre Castilrubio que «en el tiempo que este testigo los vio montes [c. 1450-1470] ni se pastan ni se avia quien andoviese por ellos por la grand espesura dellos» (AChG, c. $2709, n^{\circ} 7$, f. 33 r). Debemos considerar la importancia del bosque en Extremadura hasta las últimas décadas del siglo XV: CLemente Ramos, Julián: «La evolución del medio natural en Extremadura (1142-1525)», El medio natural en la España medieval. Actas del I Congreso sobre ecohistoria e historia medieval, CLEMENTE RAmOs, Julián (Ed.), Cáceres, Universidad de Extremadura, 2001, pp. 15-26 y 54 (mapa 1).

7. SÁnChez LoRo, Domingo: op. cit., pp. 8o-81.

8. Molenat, Jean-Pierre, Campagnes et monts de Tolede du Xle au XVe siécle, Madrid, Casa de Velázquez, 1997, p. 266; SÁnchez Rubio, Ma Ángeles: El concejo de Trujillo y su alfoz en el tránsito de la Edad Media a la Edad Moderna, Cáceres, Universidad de Extremadura, 1993, pp. 305-6.

9. AChG, caja 2709, $n^{\circ} 7$; «montes e xarales bravos», «montes bravos e xarales, «tierras de muchos montes e xarales e... sy no es algun pedaço que roçan no ay tierra rasa syno todos xarales e montes» o «montes bravos e muy espeso y muchas syerras» (AChG, c. 2709, $n^{\circ} 7$; ff. 26v, 28 r y 29 r; AChG, c. 14529, $n^{\circ} 7$, ff. $55 v$ y 103v). 
Castilrubio es una de las dehesas con monte de la tierra de Medellín. Quedan sujetas, por ello, al aprovechamiento vecinal de la montanera ${ }^{\mathrm{IO}}$. A principios de la segunda mitad del XV, la dehesa de Castilrubio se vende con «montes e prados» o montes. En las cuentas municipales de I537-I543, está sujeta a la renta de las vacas que grava a las dehesas con monte ${ }^{\text {II }}$. Este paisaje ha permitido la existencia de una importante riqueza faunística. Se citan «muchos lobos», jabalíes, venados y «otras muchas caças» ${ }^{\mathrm{I2}}$. Se alude reiteradamente a la relación entre el matorral denso y la proliferación de animales dañinos y caza. Una información que podemos situar en la década de 1450 ó poco después precisa que un vecino debió abandonar una roza porque, debido a la «bravedad de los dichos montes», las alimañas se la comían ${ }^{13}$.

La dehesa de Castilrubio presentaría a lo largo del siglo XIV, quizás desde antes, un paisaje de monte hueco o adehesado. El monte suponía una pesada servidumbre por los derechos vecinales sobre los aprovechamientos silvícolas, en particular la montanera. Esta dehesa estaría rodeada por un monte denso de encina, probablemente, o encina/alcornoque y jaral. El bosque marcaría los límites. A lo largo del siglo XV se planteará una gran dificultad en precisar unos límites definidos por una línea cambiante. Por otro lado, un espacio limitado por una densa vegetación natural podría ampliarse con la mera roturación del espacio circundante. No hablamos de una mera hipótesis. En el siglo XV, los propietarios de la dehesa se apropiarán de parcelas roturadas ampliando de forma notable su extensión. En el deslinde del siglo XIII, el castillo de Castilrubio aparece como uno de los mojones de la dehesa, que se extendía en dirección SW hacia el término de Zalamea siguiendo el curso del arroyo Tamujoso ${ }^{\mathrm{I}}$. No se alude a las dos dehesas (Zafrilla y Valdegamas) que en el siglo XV aparecerán como limítrofes, por lo que deducimos que estaban separadas por espacios de monte denso. A mediados del siglo XV, el castillo de Castilrubio estaba rodeaba de montes «bravos». El espacio entre el arroyo de la Zafrilla (quizás el actual arroyo de Pantoja) y la casa del Valdegamas «hera todo monte bravo e xaral» ${ }^{15}$.

La dehesa de Castilrubio aparece claramente perfilada entre finales del siglo XIII y mediados del siglo XV, periodo en el que se aprecia una clara continuidad. Los cambios se van a acumular a partir de esta última fecha. La dehesa se extiende en esta etapa entre el castillo de Castilrubio y el término de Zalamea a lo largo de la

10. Clemente Ramos, Julián: «El espacio pecuario en Medellín...», pp. 524-8.

11. AChG, c. $2709, n^{\circ} 7$, ff. $70 v$ y 71 .

12. AChG, c. $14529, n^{\circ} 7$, ff. 55v, 64r, 75v, $83 v$ y 93r: «puercos havalies y lovos y caça», «muchos javalies e venados e caça e muchos lobos», «javalies e venados e otras muchas caças», «havalies, venados e caças».

13. AChG, caja 2709, $n^{\circ} 7$, f. 31 .

14. «El primer mojon es Castiel-Rubio. Y como va por cima de la sierra y da en el Rincon de Castiel- Rubio como para los mojones con los de Zalamea. $Y$ va derecho por cima de la sierra como caen las aguas a Guadames. $Y$ dende como da a la fuente de la Lapa. Y torna a Guadames y pasa el rio y da en las losas de Juan Ferrus en la Xara. Y va por al Vera de la Xara y torna el primer mojon, que dicen Castiel- Rubio» (SÁNCHEZ LoRO, Domingo: op. cit., pp. 80-81).

15. AChG, c. $2709, n^{\circ} 7$, ff. 33 r y 27 r. 
cuenca del arroyo Tamujoso. El terreno está rodeado de masas forestales densas. Estos espacios, inexplotados y comunales, permiten la instalación de colmenares.

\section{CRECIMIENTO AGRARIO, USURPACIONES Y PODER (1400-C.1550)}

\section{III.1. CAMBIOS EN LA PROPIEDAD (C. 1400-C. 1475)}

La primera mitad del siglo XV se define por la continuidad. El proceso de crecimiento agrario, detonante de un proceso complejo e intenso de ampliación y apropiación de terrenos roturados, no ha comenzado o al menos no lo hemos documentado. Sin embargo, se producen cambios importantes en la estructura de la propiedad que suponen una etapa de transición entre el control de Castilrubio por un miembro del linaje Mejía y la adquisición de una participación mayoritaria por Juan de Susilla y su mujer. Desconocemos como un miembro de los Mejía llegó a controlarla. En I404, era propiedad de los hermanos Juan Núñez Mejía, comendador de Oliva y Palomas, Gonzalo Mejía y Constanza Fernández, mujer de Pedro López Fajardo, comendador de Caravaca ${ }^{16}$. No podemos situar a estos personajes de modo preciso en su entorno familiar, pero su consideración como una rama de los Mejía de Medellín no ofrece duda alguna. Las coincidencias onomásticas son evidentes ${ }^{17}$. Hay otro detalle del mayor interés. Estamos ante el ejemplo más temprano de vinculación de miembros de la oligarquía local con las órdenes militares, algo que no dejará de incrementarse a lo largo del siglo $\mathrm{XV}^{\mathrm{I}}$.

La propiedad sobre Castilrubio se ajusta a principios del siglo XV al perfil dominante en Medellín y otras zonas extremeñas ${ }^{19}$. La dehesa es detentada por miembros de la oligarquía, que no parecen tener otras propiedades. Es posible que su vinculación con las órdenes militares haya incidido en lo que parece una desvinculación patrimonial de Medellín. En todo caso, en I404 venden la dehesa a los hermanos Gonzalo García, Alonso Fernández, con sus respectivas esposas, y Juana Fernández. Se trata de vecinos «de la villa de Medellyn e moradores en Mengabril». Su residencia aldeana no ofrece problemas, no así su vecindad. La propiedad de este colectivo familiar, con algún matiz, se mantiene durante algo más de medio siglo. La venta de participaciones entre I457 y I459 (I/7, I/9 y 2/9)

16. AChG, c. $2709, n^{\circ} 7$, f. 65 r-v.

17. Clemente Ramos, Julián: La tierra de Medellín..., pp. 98-108.

18. GERBET, Ma Claude: La noblesse dans le royaume de Castille: étude sur ses structures sociales en Estrémadure (1454-1516), Paris, Université de Paris IV, 1979, pp. 358-367.

19. Clemente Ramos, Julián: La tierra de Medellín..., pp. 49-68; SÁnchez Rubio, Ma Ángeles: op. cit., pp. 244-251. 
se vincula a esta transmisión. Las dos últimas son producto claro de la división de los respectivos tercios. En I457, aparece como particionero Juan de Sandoval, regidor en I449 y homónimo de otro que aparece en I4Io como propietario de trescientas setenta y cinco vacas de hierba en las dehesas de Casalelcampo (I/2) y Retamosa $^{20}$. No sabemos cuando adquirió esta participación (2/9) que transmite en I459 a Juan de Susilla ${ }^{21}$. Este mismo año, también aparece como particionero Juan Merchán. Igualmente, su hijo Gonzalo Tome Merchán y su mujer Catalina Rodríguez, vecinos de Don Benito, adquieren una participación ${ }^{22}$.

La propiedad sobre Castilrubio durante esta primera mitad del siglo XV y principios de la segunda ofrece un perfil especial. La propiedad adehesada ha constituido en líneas generales un monopolio de la oligarquía local, plenamente constituida hacia mediados del siglo XIV. Con la salvedad de Juan de Sandoval, los compradores de I404 y sus descendientes no parecen pertenecer a este grupo. Su onomástica les presenta como simples vecinos. Su residencia se asienta en aldeas como Mengabril, Don Benito o Guareña ${ }^{23}$. No debemos olvidar el perfil exclusivamente pechero y campesino que presentan las aldeas hasta bien entrado el siglo $\mathrm{XVI}^{24}$. Onomástica y residencia refuerzan el carácter de simples vecinos de la mayor parte de los copropietarios de Castilrubio en el primer y segundo tercio del siglo XV, lo que constituye una clara anomalía. Es raro que se aluda a la existencia de lo que podemos considerar élites rurales antes de mediados del siglo $\mathrm{XV}^{25}$. La tierra de Medellín presenta ejemplos muy tempranos y suficientes desde finales del siglo XIV, pero su interpretación ofrece dudas ${ }^{26}$. Estos compradores, particioneros o copropietarios constituyen una temprana y clara manifestación de los grupos rurales enriquecidos que hemos estudiado para fechas más tardías

20. Clemente Ramos, Julián: La tierra de Medellín..., pp. 120-1.

21. AChG, c. 2709, $n^{\circ} 7$, ff. $70 v$ y $77 v$.

22. AChG, c. $2709, n^{\circ} 7$.

23. «Fernand Garçia de María serrana, vesino e morador en Mengabril.. vendo e roblo a vos Gonçalo tome Merchán e a Catalina Rodriguez, vuestra mujer, veçinos de Don Benito», «Alfon el mozo, hijo de Pedro Alonso, y Maria Sancho, su mujer, vecinos de Guareña»; «yo Juan Garçia... e yo Catalina Sanches, su muger, vesinos de Medellyn», «son partiçioneros herederos de Juan Martin Merchan, $v^{\circ}$ de Don Benito, e Gonçalo Hernandez Cavallero, $v^{\circ}$ de Mengabril, e herederos de Juan Martin Çerrato, $v^{\circ}$ de Don Benito» (AChG, c. 2709, nº 7, ff. 70v, 71r, $73 v$ y $76 v$ ).

24. Ladero Quesada, Miguel Ángel: «La caballería y la población de Extremadura según los alardes de 1502», Norba. Revista de Historia, 17 (2004), pp. 169-171.

25. Puñal Fernández, Tomás: «La ganadería lanar en Madrid y su tierra durante la Edad Media», Espacio, Tiempo y Forma. III. Historia Medieval, 11 (1998), pp. 331-381, pp. 368-370; Berges SÁNCHEZ, Juan Manuel: Actividad y estructuras pecuarias en la comunidad de Albarracín (1284-1516), Tramacastilla, Centro de Estudios de la Comunidad de Albarracín, 2009, pp. 450-459; GARcíA GARCIMARTín, Hugo Joaquín: El valle del Alberche en la Baja Edad Media (siglos XII-XV), Ávila, Diputación de Ávila, 2004, pp. 154. En otras zonas europeas, pese al incremento de las tenencias que sigue a la Peste Negra, también hay que esperar al siglo XV para el desarrollo de una élite rural consolidada o en vías de consolidación: MORICEAU, Jean-Marc: Les fermiers de l'île-de-France: L'ascension d'un patronat agricole (XV e-XVIII ${ }^{e}$ siècle). París, Fayard, 1994, Pp. 55-6 y 91-98; JACQUART, Jean: «Réflexions sur les notables ruraux: Le groupe des marchands-laboureurs en île-de-France du XV siècle à la Révolution», Congreso de historia rural. Siglos XV-XIX, Madrid, Casa de Velázquez y Editorial Complutense, 1984, pp. 647-9; Cooper, 1988, p. 183; VAN BAVEL, J. P.: «Early Proto-Industrialization in the Low Countries? The Importance and Nature of Market-Oriented Non-Agricultural Activities on the Countryside in Flanders and Holland, c. 1250-1570», Revue Belge de Philologie et d'Histoire, 81/4 (2003), p. 34; DYER, Christopher: Niveles de vida en la Baja Edad Media: Cambios sociales en Inglaterra, c. 1200-1520, Barcelona, Crítica, 1991, pp. 184-5.

26. Clemente Ramos, Julián: La tierra de Medellín..., pp. 122-3. 
a escala regional y local. Todo nos hace pensar que este grupo, con mucha menos fuerza y consistencia que un siglo después, surgen en el siglo XIV y habría que vincularlos a los enormes cambios sociales que sufre la sociedad en el contexto de la crisis bajomedieval ${ }^{27}$. No parece que estemos ante una realidad singular. En este sentido, cobra todo su significado la referencia a los labradores en las normativas suntuarias de las Cortes de Madrigal de I438, lo que nos muestra una realidad social consolidada ${ }^{28}$.

A lo largo de algo más de medio siglo, la dehesa de Castilrubio, con pastos estimados para ciento cincuenta vacas ${ }^{29}$, ha sido poseída por vecinos aldeanos de buena posición económica. A partir de I458, Juan de Susilla y su mujer Catalina García desarrollan una actividad compradora que va a permitirles disfrutar de la casi totalidad de la propiedad. En torno a I465-I475, algunos testigos les consideran propietarios exclusivos. En realidad, solo son sus mayores partícipes. En I495, los herederos de Juan Merchán disponen aún de una séptima parte ${ }^{30}$. Sin duda, esta imprecisión sobre la propiedad, compartida por muchos testigos, tiene una razón clara. A partir de 1463, con la muerte del conde Rodrigo Portocarrero, los Susilla marcarán el complejo discurrir de esta dehesa, plenamente imbricado en los procesos económicos y sociopolíticos de la corona de Castilla y de la jurisdicción medellinense.

\section{III.2. CRECIMIENTO Y CONFLICTIVIDAD: ROZAS Y USURPACIÓN DE TÉRMINOS (C. 1455-C. 1495)}

En torno a mediados del siglo XV se inicia una etapa claramente definida que se inscribe en la dinámica de crecimiento del mundo rural castellano ${ }^{3 \mathrm{I}}$. Esta coyuntura demográfica claramente alcista, que se puede documentar igualmente

27. Furıó, Antoni: «La Crisis de la Baja Edad Media: una revisión», en Furió, Antoni (coord.), Las crisis a lo largo de la historia, Valladolid, Universidad de Valladolid, 2010, pp. 13-46.

28. GONZÁLEZ ARCE, José Damián: Apariencia y poder. La legislación suntuaria castellana en los siglos XIII-XV, Jaén, Universidad de Jaén, 1998, pp. 169-170.

29. Clemente Ramos, Julián: «El vaqueamiento de las dehesas de Medellín (1460)», Norba. Revista de Historia, 18 (2005):, pp. 144.

30. AChG, C. $2709, n^{\circ} 7$, ff. $4 v$ y $37 r$.

31. Casado Alonso, Hilario: Señores, mercaderes y campesinos. La comarca de Burgos a fines de la Edad Media, Madrid, Junta de Castilla y León, 1987, pp. 143-7; GoICOLEA JULIÁN, Francisco Javier: Haro: Una villa riojana del linaje Velasco a fines del Medievo, Logroño, Instituto de Estudios Riojanos, 1999, pp. 77-81; Díaz de DuRANA, José Ramón: «El mundo rural guipuzcoano al final de la Edad Media: progreso agrícola, gestión y explotación de la tierra», En la España Medieval, 21 (1998):, pp. 177-8; García Garcimartín, Hugo Joaquín: op. cit., pp. 151-2; SuÁrez Alvarez, Maa Jesús: La villa de Talavera y su tierra en la Edad Media (1369-1504), Oviedo, Universidad de Oviedo, 1982, pp. 318-20; QUESADA QueSADA, Tomás: El paisaje rural de la campiña de Jaén en la Baja Edad Media según los libros de las dehesas, Jaén, Universidad de Jaén, 1994, pp. 43-9; SÁNCHEZ BENITO, José María: «Organización y explotación de la tierra de Huete (siglo XV)», Historia. Instituciones. Documentos, 26 (1999), p. 536. 


\begin{tabular}{|c|c|c|c|}
\hline \multicolumn{4}{|c|}{$\begin{array}{c}\text { TABLA } 1 \\
\text { DEHESA DE CASTILRUBIO: PROPIETARIOS }\end{array}$} \\
\hline AÑO & $\begin{array}{c}\text { PARTE } \\
\text { TRASPASADA }\end{array}$ & $\begin{array}{c}\text { PROPIETARIO/VENDEDOR/DONANTE } \\
(\text { * PROBABLE VINCULACIÓN CON } \\
\text { COMPRADORES DE 1404) }\end{array}$ & RECEPTOR/COMPRADOR \\
\hline 1290 & Toda & Sancho IV & Pedro Sánchez de la Cámara \\
\hline $\begin{array}{l}1404 \\
\text { (o antes) }\end{array}$ & ¿Toda? & $\begin{array}{l}\text { Juan Núñez Mejia (comend. Oliva y } \\
\text { Palomas), Mejía y Constanza Fernández } \\
\text { (mujer Pedro López Fajardo, comendador } \\
\text { Caravaca), hermanos }\end{array}$ & $\begin{array}{l}\text { Gonzalo García=María Sánchez, } \\
\text { Alonso Fernández=Mencía Martín } \\
\text { y Juana Fernández (hermana GG y } \\
\text { AF), v }{ }^{\circ} \text { Medellín «e moradores en } \\
\text { Mengabril» }\end{array}$ \\
\hline 1441 & --- & $\begin{array}{l}\text { Juana Fernández (casada con Mateos Pérez } \\
\text { de Mengabril) }\end{array}$ & \\
\hline \multirow[t]{2}{*}{1457} & $1 / 7$ & $\begin{array}{l}\text { Fernán García de Nuestra Serrana*, vo } \\
\text { Mengabril (parte su padre Juan Fernán- } \\
\text { dez el Sordo) }\end{array}$ & $\begin{array}{l}\text { Gonzalo Tome Merchán=Catalina } \\
\text { Rodríguez, v }{ }^{\text {S Don Benito }}\end{array}$ \\
\hline & parte & $\begin{array}{l}\text { Juan Merchán (padre Gonzalo Tome), } \\
\text { Juan de Sandoval y hers. Mencía }\end{array}$ & \\
\hline \multirow[t]{2}{*}{1458} & $1 / 9$ & $\begin{array}{l}\text { Alfón el mozo (hijo Pedro Alonso)= María } \\
\text { Sancho, } v^{\text {OS }} \text { Guareña }\end{array}$ & $\begin{array}{l}\text { Juan de Susilla=Catalina García, v } \\
\text { Medellín }\end{array}$ \\
\hline & parte & $\begin{array}{l}\text { Sevilla (hija Juan de Sandoval); Gonzalo } \\
\text { Fernández Caballero*, hers. Juan } \\
\text { Fernández el Sordo*, Gonzalo Merchán, } \\
\text { María Sánchez* (mujer Juan García -hijo } \\
\text { Garcí Alonso recuero-), Alfonso Martín } \\
\text { Cerrato* y hers. Juan Martín Cerrato* }\end{array}$ & \\
\hline \multirow[t]{2}{*}{1459} & $\begin{array}{l}2 \text { partes de } \\
1 / 3\end{array}$ & Juan de Sandoval, vº Medellín & Juan de Susilla=Catalina García \\
\hline & parte & $\begin{array}{l}\text { Juan Martín Merchán*, Gonzalo Fernán- } \\
\text { dez Caballero*, vo Mengabril; hers. Juan } \\
\text { Martín Cerrato*, vo Don Benito }\end{array}$ & \\
\hline 1464 & parte & $\begin{array}{l}\text { Juan García (hijo Garcí Alonso recuero y } \\
\text { quizás anterior marido de María Sánchez) } \\
\text { y su mujer Catalina Sánchez, v }{ }^{\circ} \text { Medellín }\end{array}$ & $\begin{array}{l}\text { Catalina García (viuda de Juan de } \\
\text { Susilla) }\end{array}$ \\
\hline 1468 & parte & $\begin{array}{l}\text { hers. Juan Martín Merchán, v }{ }^{\text {os }} \text { Don } \\
\text { Benito; Gonzalo Hernández Caballero, } \\
\vee^{\circ} \text { Mengabril; hers Juan Martin Cerrato, } \\
\vee^{\circ} \text { Don Benito }\end{array}$ & \\
\hline
\end{tabular}


en Medellín y en espacios limítrofes ${ }^{32}$, va a generar una ampliación del terrazgo agrario. La zona meridional del término medellinense, con una menor ocupación y un escaso número de dehesas, constituirá un espacio preferente de concesión de rozas desde mediados del siglo XV. Este proceso tendrá consecuencias evidentes en un espacio como Castilrubio rodeado por montes «bravos». Las rozas van a propiciar, en un espacio delimitado por hitos vegetales, un proceso de apropiación que podemos cartografiar con gran precisión. La importante usurpación territorial que se realiza está estrechamente relacionada con factores sociopolíticos locales y generales.

El cultivo de nuevas tierras no se documenta en la primera mitad del siglo $\mathrm{XV}$. No aparecen en un pleito de I44I sobre el aprovechamiento del pasto de Castilrubio por un propietario de colmenas ${ }^{33}$. La situación cambia en la década siguiente. La ampliación del terrazgo agrario se presenta con fuerza en vida y por iniciativa del conde Rodrigo Portocarrero (I449-I463). La concesión de rozas se realizaría a partir de $1458-9^{34}$. Un testigo sitúa por las mismas fechas, entre I455 y I460, actuaciones de Juan Merchán, uno de los particioneros de Castilrubio, «poniendo fuego en ellos [los montes bravos] por los abrir» ${ }^{35}$, con la evidente intención de ampliar la dehesa. Parece razonable afirmar que poco después de mediados de siglo, se desarrolla con fuerza la puesta en cultivo de espacios incultos para responder al aumento demográfico. No conservamos ningún listado de las rozas concedidas por el conde de Medellín, pero algunos testigos identifican hasta sesenta beneficiarios. Se trata de una cantidad, aunque parcial, significativa. Tardíamente, los testigos aluden a rozas de doce fanegas o un cahíz de sembradura ${ }^{36}$. El conde concedió una de «diez e ocho fanegadas de senbradura» ${ }^{37}$. Esto nos situaría en una extensión mínima de tierra cultivada de unas trescientas sesenta hectáreas, casi cuatro kilómetros cuadrados. Estamos ante una superficie cercana a la mitad de espacio apropiado por los Susilla.

Las rozas se situarían entre los castillos de Castilrubio y Mariejo (topónimo desaparecido, aunque permanecen los restos de la fortaleza) y el arroyo de la Bernarda y Calerueca, ya en el cauce del Guadámez (cf. Mapa 2) 38 $^{3}$. El espacio roturado sigue los cursos del arroyo Tamujoso y el río Guadámez, en dirección

32. Sánchez Rubio, Ma Ángeles: op. cit., pp. 52-5; Rodríguez Blanco, Daniel: La Orden de Santiago en Extremadura en la Baja Edad Media (siglos XIV y XV), Badajoz, Diputación de Badajoz, 1985, pp. 1985: 81-4; CLemENTE Ramos, Julián: La tierra de Medellín..., pp. 44-9.

33. AChG, c. $2709, n^{\circ} 7$, ff. $67 r-68 v$.

34. «antes quel conde don Rodrigo moriese [+1463] quatro o çinco años, el dicho conde dyo alli çiertas roças a vezinos de Don Benito e Mingabril» (AChG, c. 2709, $n^{\circ} 7$, f. 55 r).

35. AChG, c. $2709, n^{\circ} 7$, f. $37 \mathrm{v}$.

36. En relación con Castilrubio se alude a rozas de esta extensión de modo general, aunque para otros espacios aparecen extensiones más reducidas (AChG, c. 14529, $n^{\circ}$ 7, ff. 13v, 14v -preg. 10., 61v, 81v, 9ov).

37. AChG, caja $2709, n^{\circ} 7$, f. 38 r.

38. AChG, c. $2709, n^{\circ} 7$, ff. $39 v$ y 42 r: «çiertos pedaços de roças que heran en los lugares de la Caleruela e Charco de Borracha e en la bera de Castilruvio e en parats (sic) e derredor del Castil de Mariejo»; «su padre del dicho Susilla abrio otra roça junto a la de su padre deste testigo entre medias de la Posada del Conejo e del Arroyo de la Vernalda». 
noroeste. Una segunda línea de ampliación del terrazgo, siempre limitada, pudo desarrollarse hacia las estribaciones montañosas situadas al norte y al sur. Se alude a una roza junto a la Sierra de la Lapa ${ }^{39}$. En todo caso, la vegetación se mantiene por encima del nivel 400, lo que explica la existencia de topónimos de colmenares en esa cota.

Los propietarios de Castilrubio han participado en este proceso de conquista agraria con evidente interés. Ya hemos aludido a las actuaciones e intenciones del particionero Juan Merchán. También Juan de Susilla realizó un número no precisado pero estimable de rozas que cedió a algunos vecinos de Don Benito ${ }^{40}$. No parece que el conde haya tenido ninguna participación en estas actuaciones.

La ampliación del terrazgo agrario siguiendo el curso del arroyo Tamurejo, al NW de Castilrubio, era un proceso muy maduro a la muerte del conde Rodrigo Portocarrero (+ I463). La eliminación del bosque y la puesta en cultivo debió ser un proceso rápido facilitado por el uso generalizado del fuego ${ }^{4 \mathrm{I}}$. Aunque continuase luego una labor más lenta, el cambio paisajístico posiblemente originó un paisaje desarbolado.

Ampliación del terrazgo agrario y apropiaciones de términos van a ser procesos unidos y sucesivos en Castilrubio. Las usurpaciones están muy presentes durante el siglo XV en la corona de Castilla ${ }^{42}$. No estamos, por tanto, ante una realidad particular. La muerte del conde Rodrigo Portocarrero en I463 marcará no el inicio pero si la maduración del proceso. Esta fecha adquiere una importante

39. AChG, c. $2709, n^{\circ} 7$, f. $38 r$ : «a este testigo le fue dada una roça... cabe la Sierra de la Lapa, hazia el Canpillo e cabe la Fuente de Martin Cortes».

40. «su padre del dicho Susilla abrio otra roça junto a la de su padre deste testigo entre medias de la Posada del Conejo e del Arroyo de la Vernalda»; «durante este tienpo [1459-1464] vido que su padre de Rodrigo Alonso vendio algun parte de los dichos montes para labrar çiertos vezinos de Don Benito, en espiçial a Alonso Casado e Miguel Arias e otros que dizen que no se acuerda sus nonbres de ellos, los quales abrieron alli roças e cojeron pan en ella» (AChG, c. $2709, n^{\circ} 7$, ff. 42 r y $36 r$ ).

41. AChG, caja $2709, n^{\circ} 7$, ff. $26 r$ y $27 r$ : «hera pequeña e que agora con los fuegos grandes que se hizieron la heçieron grande de los montes bravos que çerca della estavan»; «mucha parte de los dichos montes bravos... fueron quemados con grandes fuegos».

42. Se trata de un fenónemo que presenta un perfil y unas consecuencias diferenciadas (ampliación de propiedades, despoblados, adehesamientos, etc.): CABrILLANA, Nicolás: «Salamanca en el siglo XV: nobles y campesinos», Cuadernos de Historia. Anexos de la Revista Hispania , 3 (1969), pp. 255-295.; CARmona Ruiz, Ma Antonia: Usurpaciones de tierras y derechos comunales en Sevilla y su tierra durante el siglo XV, Madrid, Ministerio de Agricultura, 1995; DiAgo HeRnANDO, Máximo: «Los términos despoblados en las comunidades de villa y tierra del Sistema Ibérico castellano a finales de la Edad Media», Hispania. Revista Española de Historia, 51/2 (1991), pp. 467-515; Monsalvo Antón, José María: «Paisaje agrario, régimen de aprovechamientos y cambio de propiedad en una aldea de la tierra de Ávila durante el siglo XV: La creación del término redondo de Zapardiel de Serrezuela», Cuadernos Abulenses, 17/1 (1992), pp. 11-110, y «Usurpaciones de comunales: Conflicto social y disputa legal en Ávila y su tierra durante la baja Edad Media», Historia Agraria, 24/2 (2001), pp. 89-122; CLEMENTE RAMOS, Julián: «La tierra de Galisteo (c. 1375-c. 1425). Transformaciones del poblamiento y apropiaciones ilegales», Arqueología y Territorio Medieval, 17 (2010), pp. 31-46. Las usurpaciones se han vinculado en gran medida a la baja Edad Media y en particular al siglo XV, pero se trata de un error inducido por el registro documental: el adehesamiento en Extremadura, maduro hacia 1300 y para el que no consta casi ningún título de propiedad, es sin duda como ya hemos indicado el mayor proceso de usurpación posterior a la conquista cristiana (CLEMENTE RAmOS, Julián: «Ocupación del espacio y formas de explotación. Dehesas y adehesamiento en Extremadura [c. 1250-c. 1450]», en GARCíA FITZ, Francisco y JIMÉNEZ AlCÁZAR, Juan Francisco (Coords.), La historia peninsular en los espacios de frontera: Las «Extremaduras históricas» y la «Transierra» [siglos XI-XV], Cáceres-Murcia, Sociedad Española de Estudios Medievales, 2012, pp. 262-4). 
significación si consideramos el contexto político castellano en la segunda década del reinado de Enrique IV $^{43}$. Se genera una coyuntura muy especial, con una importante inestabilidad, un agudo conflicto monarquía/nobleza y una situación de interinidad en la jurisdicción medellinense con la minoría de Juan Portocarrero, segundo conde de Medellín. Hasta I480, la jurisdicción va a ser controlada por Beatriz Pacheco, condesa viuda. Sin duda, estamos ante casi dos décadas de violencias y abusos. Más de un siglo más tarde, se guarda memoria de una coyuntura que se define como «el tiempo de los robos e alteraçiones». Un testigo señalará de modo más preciso que en este momento, que no puede referirse más que al periodo que va de $1463-4$ a I480, «qualquyera persona se entrava en los baldios del conçejo como queria syn que ninguna se lo resistiese» ${ }^{44}$. El proceso de apropiación que se produce en Castilrubio se materializa dentro de una coyuntura de enorme violencia y enfrentamientos. Beatriz Pacheco llegará a tener en prisión a su hijo Juan Portocarrero, conde de Medellín, y a diversos miembros del linaje Mejía (Catalina Mejía, Diego Mejía y Juan Núñez de Prado), el más cualificado de esta villa. La guerra civil castellana será una fuente de violencia hasta 1480 en esta jurisdicción ${ }^{45}$. La condesa y Juan Núñez de Prado, capitán en el ejército de Isabel ${ }^{46}$, combatirán en bandos rivales. Las fuentes callan sobre otros miembros de la oligarquía. Quizás sea significativo que, en I48I, Rodrigo Alonso de Susilla aparezca como alcalde mayor del conde, lo que parece indicar un distanciamiento previo de Beatriz Pacheco ${ }^{47}$. En este contexto, se realizaron importantes usurpaciones de términos en la jurisdicción por distintos miembros de nobleza local. La propia Beatriz Pacheco no es ajena a esta dinámica ${ }^{48}$. Todo nos hace pensar que estamos ante un proceso de notable incidencia.

A diferencia de estos casos, que conocemos tardíamente por las actuaciones de los jueces de términos, la conservación del pleito de I495 nos permite precisar con gran detalle el proceso de apropiación en Castilrubio. El deslinde del siglo XIII nos permite disponer de una referencia anterior y contrastar la información de los testigos. La probanza de Rodrigo Alonso de Susilla transmite una imagen plana (todo Castilrubio era de Juan de Susilla, que siempre disfrutó de todos los términos y los transmitió a su heredero) que no se ajusta a la realidad. Los testigos

43. SuÁrez Fernández, Luis: Nobleza y monarquía. Puntos de vista sobre la historia política castellana del siglo XV, Valladolid, Universidad de Valladolid, 1975, pp. 203-242; PÉrez Bustamante, Rogelio y CaLderón OrTega, José Manuel: Enrique IV, 1454-1474, Burgos, Editorial La Olmeda, 1998, pp. 149 ss.; DeL PINO GARCíA, José Luis: Extremadura en las luchas políticas del siglo XV, Badajoz, Diputación de Badajoz, 1992, pp. 220-291.

44. AChG, c. $14529, n^{\circ} 7$, ff. $70 v$ y, en el mismo sentido, 6ov; sobre la expresión señalada, ff. 24r, 33v, 42r, y 8or.

45. El testamento de Beatriz Pacheco recoge lo que pudieron ser ciertas violencias (GARCíA SÁnCHEZ, Francisco: La Condesa de Medellín: Da Beatriz de Pacheco, Medellín, edic. personal, 1997, p. 147). En general, Del PINo García, José Luis: Extremadura en las luchas políticas..., pp. 296-8.

46. Bernáldez, Andrés, Memorias del reinado de los Reyes Católicos (edic. y estudio por Manuel Gómez-Moreno y Juan de Mata Carriazo), Madrid, Real Academia de la Historia, 1962, p. 597.

47. AChG, caja 2709, $n^{\circ}$ 7, f. $75 v$ (13 de marzo); Archivo Monasterio de Guadalupe, leg. $99 n^{\circ} 22$, f. 20 r (29 de junio)

48. Clemente Ramos, Julián: «La ganadería en Medellín (1450-1550): propietarios y cabañas», Anuario de Estudios Medievales, 44 - 2 (2014), p. 814 . 
de Medellín señalan con claridad como con la muerte del conde Rodrigo Portocarrero se hace efectiva la apropiación de los terrenos nuevamente roturados por Rodrigo Alonso de Susilla, al que se presenta como único propietario ${ }^{49}$. En un pleito sobre un colmenar en I48I, la justicia local falla a favor de los propietarios de Castilrubio o Zafrilla. A esto no debió ser ajeno la condición de alcalde mayor de Rodrigo Alonso de Susilla. Lo llamativo es que el colmenar se asienta en un terreno que no está claro si pertenece a la dehesa de Castilrubio o de la Zafrilla, lo que nos permite afirmar que se asienta en la parte apropiada desde hacía casi dos décadas y que se acepta la condición de limítrofes de ambas dehesas, algo no documentado con anterioridad. Seguramente se trate de uno de los colmenares que se documentan en el siglo XV en el límite de las zonas roturadas ${ }^{50}$.

La apropiación, sin embargo, no se materializa de forma completa y efectiva hasta la sentencia de I495. Hacia I475 y con más claridad desde I480, fecha que marca el control real de la jurisdicción, el concejo de Medellín intenta revertir la apropiación. El espacio roturado abría en teoría este espacio a un más amplio aprovechamiento vecinal. En los límites del nuevo espacio roturado se instalan colmenares que debió conceder el concejo de la villa. Las boyadas de Medellín, Don Benito y Mengabril se desplazan a la zona para aprovechar seguramente los pastos. Sin duda, estamos ante un enfrentamiento enconado por el espacio que no consistió simplemente en la realización de prendas por los propietarios y que debió originar en ocasiones un aprovechamiento compartido ${ }^{\mathrm{I}}$. Es llamativo, sobre el particular, un suceso acaecido con la boyada de Mengabril. Rodrigo Alonso de Susilla, en su intento por expulsarla, llegó a matar un buey. Su reacción, sin embargo, fue muy significativa. Tras esto, «andovo huydo çiertos días» y, en ello coinciden dos testigos, terminó pagando el valor del animal ${ }^{52}$. Sin duda, los propietarios de Castilrubio y en particular Rodrigo Alonso de Susilla, su mayor partícipe, se enfrentaron a una auténtica reacción vecinal contra sus apropiaciones.

El concejo de Medellín también intentará constituir en la Posada del Conejo, entre las dehesas de Castilrubio, Zafrilla y Peñalobar, un baldío sobre un espacio que anteriormente tenía «un gran monte» atendiendo quizás a previas indicaciones del conde Rodrigo Portocarrero ${ }^{53}$. Posiblemente se trataría de un espacio

49. «despues quel conde murio el dicho Rodrigo Alonso dixo ser suyo, e los despojo dello, e ha tenido e tiene fasta oy dia asi las dichas roças como mucha parte de los montes bravos» (AChG, caja 2709, $n^{\circ}$ 7, f. 37V; en el mismo sentido, f. 38v). Una situación similar se produce en el último cuarto del siglo XIV en Galisteo con la muerte del conde Sancho de Alburquerque (Clemente Ramos, Julián: «La tierra de Galisteo...», pp. 38).

50. AChG, caja $2709, n^{\circ} 7$, ff. $75 v-76 r$.

51. «vio andar la boyada del conçejo de Medellin al arroyo de Casatejada e dezian los que alli andavan que hera baldio e que este testigo antes que esto fuera un año de muchas aguas e que corrio de alli la boyada pero que todavia que estovo alli e no se fueron» (AChG, caja 2709, $n^{\circ} 7$, f. 6or; sobre la boyada de Don Benito, f. 41r).

52. AChG, caja $2709, n^{\circ} 7$, ff. $37 r$ y $41 v$.

53. «çierto pedaço de tierra que esta entre Castilruvio e la Çafrilla e Peñalobar puede aver veynte años [c. 1475] quel conçejo lo ha fecho baldyo, que hera un gran monte, pero que no sabe sy era de Castilruvio si de la çafrilla sy de Peñalobar, pero que oyo desir quel conde don Rodrigo lo avia mandado» (AChG, caja 2709, $n^{\circ} 7$, f. 47 r; igualmente, ff. $44 r, 49 v, 54 r-v, 56 v$ y $58 r$ ). 
limitado. Un testigo lo llama «exidillo» 54 . Los vecinos han llevado allí sus rebaños de vacas, ovejas, cabras y cerdos. Igualmente, han establecido zahúrdas y colmenares ${ }^{55}$. Hacia I492-3, poco antes de que sentenciara el pleito el juez Peñalver, Medellín continuaba intentando consolidar el control sobre ese espacio ${ }^{56}$.

Estas actuaciones de Medellín van unidas a los pleitos que interpuso contra Rodrigo Alonso de Susilla y, en general, contra otros muchos miembros de la oligarquía por diversas apropiaciones. Estas iniciativas se enmarcan dentro de las directrices establecidas en las Cortes de Toledo de I480 sobre la restitución de términos ${ }^{57}$. El juez Molina dictará sentencia sobre Castilrubio hacia I490. No tenemos claro en qué sentido ${ }^{5}$. Lo que si sabemos es que, ese mismo año, el conde Juan Portocarrero emitirá una sentencia favorable a miembros de la oligarquía que habían realizado importantes apropiaciones. Esta sentencia, que parecía interferir la actuación del juez Molina, se emitió en un contexto de «mucha y estrecha amistad» entre el conde y los partidarios de Juan Núñez de Prado, cabeza indiscutida de la oligarquía local. Esta oligarquía unía a esa amistad un control del concejo local. Rodrigo Alonso de Susilla era alcalde de los hidalgos y Pedro de Saavedra, procurador, «criado e mucho familiar del dicho Juan Nuñes de Prado $\$ 59$.

La sentencia del juez Peñalver de 1495 cierra un periodo de más de tres décadas de un modo sorprendente. Representante del poder real, fallará a favor de los propietarios de Castilrubio. La existencia de esta apropiación no ofrece dudas. La coincidencia entre el deslinde de finales del siglo XIIl y la información de los testigos la ratifican. El juez Peñalver, fundamentándose en la sentencia condal, de dudosa legalidad, adjudica los términos en disputa a Rodrigo Alonso de Susilla, considerando que el concejo, que mantiene los derechos comunales de «cortar leña e madera e comer la bellota», no ha sido «despojado de cosa alguna» ${ }^{60}$. El proceso de apropiación, que comienza tres décadas antes en un contexto crítico y es una herencia clara de una etapa de desórdenes, termina siendo sancionado por un poder real definitivamente consolidado. El apoyo del conde y el poder de la oligarquía pudieron con una rica y documentada probanza de Medellín. Los principios sobre restitución de términos de las Cortes de Toledo de I480 no se cumplen en este caso y de modo general parece que tampoco en otros sobre los que sólo disponemos de información parcial.

54. AChG, caja $2709, n^{\circ} 7$, f. 57 r.

55. AChG, caja $2709, n^{\circ} 7$, especialmente ff. $41 \mathrm{rr}, 49 \mathrm{v}$ y $50 \mathrm{v}$.

56. «puede aver dos años o tres años [c. 1492-3] que lo oyo desir que hazen valdyo çierta parte de montes que esta entre medyas de una dehesa e otra ca Castiruvio e de la Çafrilla» (AChG, caja 2709, n 7, f. 48v).

57. Cortes de los antiguos reinos de León y de Castilla, tomo IV, Madrid, Real Academia de la Historia, 1882, pp. 154-157.

58. Rodrigo Alonso de Susilla afirma que «se hicieron probanzas y se dio sentençia definitiva en mi favor a consentimiento del conçejo de la dicha villa», pero sus propios testigos no avalan esta informacíón (AChG, c. 2709, $n^{\circ} 7$, ff. $44 \mathrm{v}, 51 \mathrm{v}, 54 \mathrm{v}$ y $56 \mathrm{v}$ ).

59. AChG, caja $2709, n^{\circ} 7$. f. $88 \mathrm{v}$

6o. AChG, caja $2709, n^{\circ} 7$, f. $94 \mathrm{v}$. 


\section{III.3. ROZAS Y CONFLICTIVIDAD (1500-C. 1545)}

A lo largo de gran parte del siglo XVI se mantiene la coyuntura alcista definida por el crecimiento de la población y el terrazgo cerealista ${ }^{61}$. En Medellín, por las razones indicadas, la ampliación del terrazgo agrario se localiza de modo preferente en la zona suroriental de la jurisdicción. Por ello, los problemas de límites prosiguen en esta centuria. Sorprende, sin embargo, que la sentencia del juez Peñalver en 1495 no haya generado oposición. Las rozas concedidas por Medellín entre 1537 y 1543 dejan este espacio fuera de cualquier disputa. Se sitúan próximas al Guadámez (Cerro del Conejo, sierras de la Mancha o la Lapa) ${ }^{62}$. Dentro del pleito conservado de 1545 , los puntos de fricción se sitúan en la linde con la dehesa de la Zafrilla y el río Guadámez, en los márgenes de la apropiación materializada en el último cuarto del siglo XV.

Esta circunstancia no debemos considerarla ajena a las condiciones de la política local. Aliado inicialmente de Juan Núñez de Prado $^{63}$, que lideraba la oligarquía local enfrentada al conde, desde un momento que no podemos precisar pero posterior a 1520 , Hernando de Susilla, propietario de Castilrubio, se convertirá en un personaje fundamental en Medellín por su proximidad a Juan Portocarrero, tercer conde de Medellín (I527-I546). Un testigo dirá de él que «no se hazia en todo el condado de Medellin mas de lo quel dicho Hernando de Sosilla queria y mandava porque hera muy favoresçido e allegado de los dichos condes de Medellin» ${ }^{64}$. Entre I534 y su muerte, ocurrida a principios de la década siguiente, ocupará los cargos de mayor importancia (alcalde mayor o alcaide). Uno de sus hijos será paje del conde ${ }^{65}$. Hernando de Susilla fue, sin duda, un fiel servidor del poder condal ${ }^{66}$.

La concesión de rozas concejiles continuó en el siglo XVI. No podemos trazar una cronología precisa. Se documentan en las actas concejiles de I537-I543. En su mayor parte, se ubican como hemos indicado en las zonas colindantes a Castilrubio. Esto ha debido generar algunos roces sobre los límites de la dehesa. Entre I500 y 528 no documentamos ningún problema, quizás debido a la discontinuidad del registro documental. En I528, el licenciado Cenizales, alcalde mayor, visitó y quizás limitó la mojonera de Castilrubio. La dehesa debió aumentar su extensión

61. ANES, Gonzalo: Las crisis agrarias en la España moderna, Madrid, Taurus, 1970, pp. 92-100; López-SALAZAR PÉrEZ, Jerónimo, Estructura agraria y sociedad rural en La Mancha (siglos XVI- XVII), Ciudad Real, Instituto de Estudios Manchegos, 1986, pp. 165-182; Melón JIMÉNeZ, Miguel Ángel y RodríGuez GrajerA, Alfonso: «Crecimiento demográfico y extensión de cultivos en Coria y su tierra durante el siglo XVI», Norba. Revista de Historia, 6 (1985), pp. 171-174; PEREIRA IGLESIAS, José Luis: «La trashumancia en zonas de invernadero: el ejemplo de la tierra de Cáceres», en RuIz MARTíN, Felipe y GARCíA SAnz, Ángel (eds.): Mesta, trashumancia y lana en la España moderna, Barcelona, Crítica, 1998, pp. 85-87.

62. Archivo General de Simancas, Consejo Real (=AGS-CR), leg. 140, nº 2-II, ff. 177r, 18or, 18gr, $201 \mathrm{r}, 223 \mathrm{~V}$.

63. AGS-CR, leg. 56, exp. 2, f. 12r; A. G. Simancas, Patronato Real, leg. 6, $n^{\circ} 12$.

64. AChG, C. 14529, $n^{\circ} 7,62$ r.

65. AGS-CR, legs. 140, $n^{\circ} 4 / 2$, f. 15r, y 87, exp. 14, f. 133v; AChG, c. $767, n^{\circ} 18$, f. 6 r.

66. En el pleito sobre las elecciones concejiles en Medellín (1537-1543), Hernando de Susilla no quiso jurar como testigo del conde, pero escondió documentación fundamental que podría haberle inculpado (AGS-CR, leg. 230, exp. 2-1, f. 2r). 
por las compras de Hernando de Susilla ${ }^{67}$. Poco después, hacia I530, las partes pidieron un juez de términos, para lo que fue cometido el licenciado Verdugo. Aunque la información que tenemos sobre este pleito y su sentencia es indirecta, todo parece indicar que la villa obtuvo un fallo favorable, si bien se cedió un pequeño terreno seguramente comunal a Hernando de Susilla ${ }^{68}$. Es posible que éste apelara la sentencia ${ }^{69}$.

El deslinde del juez Verdugo no solucionó los problemas en una zona con una importante presión vecinal. Las fricciones y disputas ocasionadas por límites se mantuvieron. Sabemos que hacia 1532, un grupo de vecinos de Don Benito (Francisco Moro, Juan del Seto, Pedro Liviano, viuda de Andrés Aparicio y Rodrigo de Paredes) realizaron rozas en los límites o dentro de Castilrubio. Las sentencias emitidas contras ellos por el juez Toro en 1534 (Antón García de Cañamero, Juan del Seto, Diego Ruiz, Pedro de Paredes, Alonso López, Mari García, Juan de Paredes y Fernando Dorado) permitirán reintegrar a la dehesa el espacio en disputa ${ }^{70}$. Estas rozas se sitúan hacia el noroeste de Castilrubio, junto a la dehesa de la Zafrilla ${ }^{71}$.

Estas sentencias no supusieron una solución definitiva ni siquiera para la cuestión juzgada. Tras la muerte de Hernando de Susilla hacia I54I-2, las relaciones entre la familia Susilla y el conde cambian considerablemente. Pese a ello, mientras los copropietarios parecen confiar en el alcalde mayor, ante el que recurren, no sucede así con Medellín, que quiere separarle del futuro pleito arguyendo que el asunto estaba bajo la justicia real. La fuerte enemistad del conde con Martín de Alarcón, hijo de Catalina de Susilla y sobrino del Hernando de Susilla, explica sin embargo que el conde anime a los labradores a que se apropien terrenos de Castilrubio $^{72}$. No es extraño por ello que, hacia 1543 , se volvieran a cultivar las rozas previamente abandonadas. Solamente se cita de forma explícita a Juan del Seto y a Pedro Liviano ${ }^{73}$. Sin duda, esta coyuntura explica el acuerdo de los propietarios con Antón García de Cañamero y Fernando Dorado. Estos ceden las tierras a los herederos de Hernando de Susilla y las reciben en censo por una renta anual muy módica de «media hanega de trigo ruvio e media hanega de çevada» en un caso $\mathrm{y}$ «un hanega de trigo» en otro ${ }^{74}$. Los copropietarios intentan de este modo ase-

67. AChG, c. $14529, n^{\circ} 7$, f. 90.

68. Juan Pérez señala que el juez dio a Medellín «las tierras sobre que se litiga porque heran suyas e dexó al dicho Hernando de Sosilla un pedaço de tierra de dehesa en el dicho Castilruvio» que según oyó «no hera suya sino que hera tierra e baldios de la dicha villa de Medellin e su condado» (AChG, leg. 14529, $n^{\circ}$ 7, f. 28r). En un provisión de Carlos I se indica que la villa dio por bien empleados los maravedis gastados en el deslinde de Castilrubio y otras dehesas por un juez real, seguramente el licenciado Verdugo, lo que parece indicar un resultado satisfactorio (AChG, caja $792, n^{\circ}$ 1, f. 15 r).

69. En un pleito algo posterior se alude a ese pequeño trozo pero se indica que apelan los hijos de Hernando de Susilla y su hermana Catalina, lo que no parece probable. Quizás se trate de un error (AChG, caja 2833, n² 2, cuad. 2, f. 6or).

70. AChG, caja $2833, n^{\circ} 2$, cuad. 2, ff. $25 \mathrm{r}-38 \mathrm{v}$; algunos de ellos renuncian por escrito a sus cultivos: ff. $43 \mathrm{v}-51 \mathrm{v}$.

71. AChG, caja $2833, n^{\circ} 2$, cuad. 2, f. 64r, 69 r y $70 v$.

72. AChG, caja $2833, n^{\circ} 2$, cuad. 2 , f. $58 \mathrm{v}$ y $62 \mathrm{v}-63 \mathrm{r}$ ( «favoresçio a los labradores de la tierra para que traxesen el dicho pleito por pasion que tenia de Martin de Alarcon»).

73. ChG, caja $2833, n^{\circ} 2$, cuad. 2 , ff. $57 \mathrm{v}, 61 \mathrm{r}$ y $64 \mathrm{v}$.

74. AChG, caja $2833, n^{\circ} 2$, cuad. 2 , ff. $41 \mathrm{lv}-43$ r. 
gurarse la propiedad sobre las tierras en disputa aunque sea a costa de cederlas temporalmente en condiciones muy favorables.

La conflictividad originada por la realización y/o concesión de rozas por labradores de la tierra de Medellín continuó en la segunda mitad del siglo XVI. Se conserva una probanza del concejo de Medellín de 1570, que plantea una reivindicación general sobre espacios apropiados, aunque no se precisan con nitidez. Todo nos hace pensar que se mantienen las disputas sobre los límites entre Castilrubio y los baldíos de Medellín. Los propietarios de la dehesa han falsificado documentos, que no se copian en el pleito, supuestamente realizados por escribanos que los testigos no recuerdan ${ }^{75}$. Estas escrituras parecen distintas de las presentadas en pleitos anteriores y sobre las que no se indica su falsedad. Esta probanza nos da información muy interesante sobre el paisaje y los pleitos anteriores de Castilrubio, pero muy poca información precisa sobre las circunstancias concretas de la fecha en que se realiza.

\section{FORMAS DE EXPLOTACIÓN (C. 1450-1545)}

La dehesa de Castilrubio va a presentar un paisaje mixto, agrario y pecuario, en el tercer cuarto del siglo XV como consecuencia del proceso de roturación que se ha desarrollado siguiendo los cursos del arroyo Tamujoso y el río Guadámez. El paisaje irá adquiriendo hacia I475 un perfil más homogéneo. Es probable, aunque ninguna fuente alude a ello, que las nuevas tierras roturadas se presenten desarboladas frente a la antigua dehesa, que contaba con monte y por ello se sujetaba a la servidumbre, entre otras, de la montanera vecinal. El uso generalizado del fuego en zonas de densa vegetación hacía muy difícil la conservación parcial del arbolado.

Junto a los límites de Castilrubio, antiguos o nuevos, proliferan los colmenares, que eran concedidos por la villa. Situados en lugares periféricos y dotados de un modesto coto redondo, podían convertirse y en algún caso se convirtieron en un peligro para los baldíos comunales. La abundante vegetación creaba condiciones ideales para la explotación apícola ${ }^{76}$. Esto no dejó de producir roces con los propietarios de la dehesa. Es muy llamativo que la toponimia conservada relativa a los colmenares se sitúe en el límite entre la dehesa y los relieves que la rodean al norte y al sur, sobre el nivel 400, o en los límites con el maestrazgo alcantarino. La ampliación de la dehesa produjo la instalación de colmenares en los nuevos límites entre las tierras desbrozadas y el monte bravo. Documentamos, de este

75. AChG, c. $14529, n^{\circ} 7$, ff. 10v-12r.

76. Carmona Ruiz, Ma Antonia, «La apicultura sevillana a fines de la Edad Media», Estudios Agrosociales y Pesqueros, 185 (1999), pp. 132-3; SEgRELLES SERRANO. José Antonio: «La apicultura valenciana: un aprovechamiento agrario tradicional», Cuadernos de Geografía, 45 (1989): p. 85; SÁNCHEZ BenITO, José María: «Aproximación al estudio de un sector económico en Castilla a fines de la Edad Media: la explotación colmenera», Hernán Cortés y su tiempo. Actas del Congreso Hernán Cortés y su tiempo. V Centenario (1485-1985), Guadalupe-Cáceres-Medellín], 1985, vol. 1, Mérida, 1987, p. 100. 
modo, los colmenares de Vicente García, entre el castillo de Mariejo o Cerro del Castillo, o del Conejo y las Merchanas, próximos al Guadámez y en el límite noroeste de la dehesa.

No tenemos ninguna información sobre las formas de explotación de la dehesa de Castilrubio hasta mediados del siglo XV. Desde que se inicia la concesión de rozas, el espacio roturado y propiamente la dehesa de Castilrubio presentan, como hemos indicado, dos paisajes muy diferentes. En el primero se ha asentado, por el uso del fuego, un paisaje agrario quizás completamente desarbolado. En este espacio se asientan fundamentalmente rozas de una extensión importante concedidas por el conde. Muy probablemente se ha originado un terrazgo agrario compacto. La roza de Miguel Arias, concedida por Rodrigo Alonso de Susilla, y otras dadas por el conde eran limítrofes ${ }^{77}$. Lo mismo sucedía con las del padre de Juan Gallego y de Juan de Susilla, situadas junto al arroyo de las Bernardas y la Posada del Conejo ${ }^{78}$. El espacio roturado se siembra de «pan». Un testigo hablará de «pan e serojo»79. Sus rastrojos fueron aprovechados por los vecinos. Juan de Carmona anduvo en ellos «con puercos» ${ }^{80}$. No se alude a la imposición de ningún terrazgo. En las décadas siguientes, las rozas concedidas por Medellín tampoco estarán sujetas a ninguna renta.

En torno a I455, la dehesa de Castilrubio estaba arrendada para su aprovechamiento por vacas. No conocemos el nombre de los arrendatarios aunque sí el de algunos vaqueros (Fernando García Caballero y Pedro García Vaquero, vecinos de Villagonzalo y Manchita). Uno de ellos nos indica que podían pastar un centenar de reses $^{81}$. Su capacidad ganadera se estimó en ciento cincuenta vacas de hierba en I460. En esta primera etapa, también se aprovechó directamente por los propietarios. Probablemente entre I455 y I457, las vacas de Juan de Susilla pastaron total o parcialmente la dehesa. No es sorprendente si consideramos que antes de la compra de una parte sustancial de la misma arrendó reiteradamente a Medellín, ignoramos si de forma compartida o exclusiva, el propio-dehesa del Canchal ${ }^{82}$.

Entre I457 y I465, la dehesa estuvo arrendada durante ocho años a un grupo de labradores de Don Benito (Juan Alguacil, Pedro Fernández Caro, Bartolomé Martín Herrero, Rodrigo Alonso ¿el Porquero?, Alonso Casado, Aparicio García, Ferrando Alonso Palomero, Alonso Cazador, Aparicio Gómez, Gonzalo Miguel, Juan de Quintana, quizás alguno más). El grupo original de arrendatarios hizo

77. «que junto con la roça que este testigo tenia de Rodrigo Alonso, dio el conde don Rodrigo [rozas] a Hernand Martin de Carmonita e a Juan Gil e a Alonso Fernandes vente e quatro e a Diego Díaz e otros muchos vezinos de Don Benito» (AChG, c. 2709, $n^{\circ} 7$, f. 37v).

78. «su padre del dicho Susilla abrio otra roça junto a la de su padre deste testigo entre medias de la Posada del Conejo e del Arroyo de la Vernalda» (AChG, c. 2709, $n^{\circ} 7, \mathrm{f} .42 \mathrm{r}$ ).

79. AChG, c. $2709, n^{\circ} 7$, f. $39 \mathrm{v}$.

8o. AChG, c. $2709, n^{\circ} 7$, f. $36 \mathrm{v}$.

81. AChG, c. $2709, n^{\circ} 7$, ff. $57 \mathrm{r}$ y $59 \mathrm{v}$. No parece creíble, dado el limitado número de vacas que aprovechaban la dehesa, la información de Fernando García Caballero de que pastaban en las zonas roturadas nuevamente.

82. AChG, C. $5304, n^{\circ} 13$, f. 21 . 
partícipe del arrendamiento a otros vecinos («los quales labradores acogian a otros y ellos y otros los que ay entraron por mano de aquellos que arrendaron al dicho mi padre»). La dehesa se sometió a una explotación a pasto y labor que se ajustaba al perfil de los arrendatarios y a la demanda creciente de tierras. El conjunto de labradores pagaba una renta mixta en dinero y cereal. Quizás esta última tuviera un carácter parciario. Juan Robles, que tenía una prima entre los arrendatarios, señala que pagaban «un sesmo», renta que nos parece elevada ${ }^{83}$. Aparicio Gómez nos da detalles importantes. Indica como tuvo en la dehesa «çiertas roças» de Juan Alguacil y otros labradores que «dezian que tenian arrendada la dehesa». Al ser copartícipe del arriendo, pagó la renta «de pan en trigo e çevada de un año dellos». La participación de Aparicio Gómez debió limitarse a las rozas y sólo por un año. Estos labradores arrendaban los rastrojos. Juan Sánchez Palomo, también vecino de Don Benito, arrendó «todos los rastrojos» para su vacas» ${ }^{84}$. Esta cesión contribuyó asimismo a la ampliación de la dehesa puesto que todo parece indicar que los arrendatarios roturaron parcelas y las integraron en Castilrubio ${ }^{85}$.

La muerte del conde Rodrigo Portocarrero en I463 y la inestabilidad política castellana entre I464-I474 permite la apropiación por Rodrigo Alonso de Susilla de las rozas concedidas por la autoridad jurisdiccional. Se agregan a la dehesa de Castilrubio las rozas realizadas por propietarios y arrendatarios en años anteriores. La dehesa incrementa considerablemente su espacio y su capacidad ganadera ${ }^{86}$. A partir de 1463, asistimos a su cesión en arriendo para su aprovechamiento ganadero. Sin embargo, el espacio apropiado de forma total o parcial va a ser cedido según un informado testigo a «diez e ocho personas» que pagaron una renta de «çinquenta fanegas de pan mediado de renta trigo e çevada por ocho años» ${ }^{87}$. Suponemos que estos cultivadores retendrían temporalmente sus propias rozas, con lo que estaríamos ante una renta módica (alrededor de media fanega por fanega

83. En Valdedetorres, aldea de Medellín, hemos documentado a lo largo del siglo XV rentas parciarias mas moderadas, de un doceavo o un veinteavo; en el señorío de Feria o en La Codosera (1517) las rentas parciarias se sitúan en el diezmo. En entornos regionales próximos, se documentan rentan más elevadas (CLEMENTE RAmos, Julián: «Valdetorres, de dehesa a aldea (1409-1510). Poblamiento, conflicto y poder en la tierra de Medellín», Studia Historica. Historia Medieval, 20-21 [2002-3], p. 52; MAZO ROMERo, Fernando: El condado de Feria [1394-1505]. Contribución al estudio de régimen señorializador en Badajoz, Badajoz, I. C. Pedro de Valencia, 1977, pp. 451-5; FranCo SILVA, Alfonso: «La Codosera: La repoblación de una villa fronteriza en tierras de Badajoz», Estudios sobre D. Beltrán de la Cueva y el ducado de Alburquerque, Cáceres, Universidad de Extremadura, 2002, p. 186; MONSALVo ANTón, José María: «La ordenación de los espacios agrícolas, pastoriles y forestales del territorio abulense durante la baja Edad Media», en DEL SER QUIJANO, Gregorio (ed.), Historia de Ávila. IV. Edad Media (siglos XIV-XV). $2^{a}$ parte, Ávila, Institución Gran Duque de Alba, 2009, p. 391; Carrasco Tezanos, Ángel: La sociedad campesina en la sierra de Guadarrama a finales de la Edad Media, Madrid, A.C. Al-Mudayna, 2006, pp. 131).

84. AChG, caja $2709, n^{\circ} 7$, ff. $44 r, 46 v, 49 r, 50 r, 50 v, 57 r, 57 v$.

85. Juan Palomero señala que «aro en la dicha dehesa e fizo roças con su padre que te(nia) arrendada a Castilruvio con otros vezinos de Don Benito (AChG, 2709, $n^{\circ} 7$, f. $57 \mathrm{v}$ ).

86. Un vecino de Villagonzalo, como ya hemos indicado parcialmente, «la pasto [Castilrubio] con çien vacas, e que despues la vido pastar e pastan con dozientas e treynta vacas», cantidad muy superior a su capacidad ganadera estimada en 1460 (AChG, caja $2709, n^{\circ} 7$, f. 59r).

87. AChG, C. $2709, n^{\circ} 7$, f. $39 v$. 
efectivamente cultivada y en torno al io \% de la producción). Sin duda, esta cesión suponía la aceptación implícita de la nueva propiedad sobre el espacio roturado.

En líneas generales, Castilrubio se cede a ganaderos para el aprovechamiento del pasto en el último tercio del siglo XV. No debió ser ajeno a esta circunstancia el incremento del precio de las hierbas ${ }^{88}$. Conocemos la identidad de varios de los propietarios de ganado que arrendaron la dehesa. Predominan los aldeanos acomodados, denotando la madurez de este colectivo. Esta dehesa fue aprovechada por el padre de Alonso de Mera (Mengabril -Medellín-) en algún momento del periodo I460-I470; Alonso Sánchez Zamarra (Cristina - id.-) hacia I475-I479; y Alonso López, carnicero del rey, seguramente entre I482-I485. En I483, el agostadero se arrendó por tres mil maravedís a Gómez Núñez, Pascual Fernández y Diego Fernández, vecinos de Aldea del Valle (¿Valle de la Serena?) ${ }^{89}$. En algún momento, la dehesa fue aprovechada por las vacas de Rodrigo Alonso de Susilla, su principal y quizás único propietario a finales del XV. Debió ser algo infrecuente. En su interrogatorio, el arrendamiento ganadero se presenta como la forma habitual de explotación ${ }^{90}$.

A lo largo del siglo XVI, con unos pastos que continúan subiendo ${ }^{91}$, la forma de explotación debió mantenerse. Disponemos de poca información pero todo apunta a unas pautas similares. Al margen del acensamiento de dos rozas para consolidar la definitiva renuncia de sus desbrozadores ${ }^{92}$, Castilrubio se arrendó entre 1535 y I545 a serranos, a Hernando Esteban (Mengabril) y a Alonso Hernández (Aldea del Valle). Hernando Esteban indica que cuando «la pastaba con su ganado que no la aravan» ${ }^{93}$. Es probable que, en la primera mitad del siglo XVI, Castilrubio tuviera un aprovechamiento casi exclusivamente pecuario.

Entre mediados del siglo XV y mediados del XVI, las líneas generales se presentan con claridad. Élites aldeanas, de modo preferente, arriendan la dehesa para su aprovechamiento ganadera. La explotación a pasto y labor parece secundaria y sólo se documenta de forma precisa a comienzos de la segunda mitad del siglo XV. La disputa que originan las rozas obliga a considerar su cesión temporal para su aprovechamiento agrario. Se trata de un mecanismo transitorio que intenta consolidar la apropiación/usurpación o la renuncia de los vecinos implicados.

88. Gerbet, Ma Claude: La noblesse..., p. 81; Clemente Ramos, Julián: «La ganadería en Medellín...», pp. 832-6. En la ordenanza de los «quartos» de las dehesas de Álvaro de Estúñiga, señor de Plasencia, se precisa que los propietarios de dehesas recibían «por el pasto de las yervas grandes quantías de maravedís, mucho más de lo que por ellas solían dar [los labradores], y por esta causa no se labravan por pan en esta mi çiudad y su término, en aquella manera que hera nesçesario según la poblaçión de la dicha çiudad y su tierra» (CLEMENTE RAMOS, Julián: «La ganadería en Medellín...», p. 834, n. 115).

89. ChG, c. $2709, n^{\circ} 7,30 v, 52 r, 58 r$ y $76 r$.

90. AChG, caja 2709 , ff. $43 v$ y 52 r.

91. Pereira Iglesias, José Luis: «La trashumancia...», pp. 245; López-Salazar Pérez, Jerónimo: Mesta, pastos y conflictos en el Campo de Calatrava durante el siglo XVI, Madrid, CSIC, 1987, pp. 26.

92. AChG, c. $2833, n^{\circ} 2$, ff. $41 v-43 r$, a. 1544.

93. AChG, c. $2833, n^{\circ} 2$, cuads. 1,f. $9 r$, y 2 , ff. $64 v$ y $69 v$. 


\section{CONCLUSIONES}

La disponibilidad de diversos pleitos sobre la dehesa de Castilrubio nos ha permitido trazar la evolución de esta dehesa medellinense entre el siglo XIII y el XVI. Castilrubio era una dehesa con arbolado y con una capacidad estimada de ciento cincuenta vacas de hierba. Se sitúa en el suroeste del término de Medellín, donde aparece una serie de relieves residuales muy arrasados. La ocupación hispano-cristiana privilegió las zonas llanas y sedimentarias. Por ello, esta zona fue objeto de una menor apropiación y albergaba la mayor reserva de baldíos del término.

Desde un momento que no podemos precisar y al menos en la primera mitad del XV, la dehesa de Castilrubio estaba literalmente rodeada por una densa vegetación. El crecimiento demográfico va a propiciar la concesión de rozas en sus márgenes a principios de la segunda mitad del XV. La muerte del conde de Medellín en I463 y la violencia dominante en Castilla posibilitarán la usurpación del espacio roturado. Esta parece ser la intención de algunas iniciativas roturadoras de los copropietarios. La dehesa se ampliará, de este modo, hasta el cauce del Guadámez, en los límites de las dehesas de Valdegamas y Zafrillas, de las que anteriormente les separaba una densa vegetación. Pese a que desde I480, cuando el poder real queda asentado de modo efectivo en Medellín, este concejo intenta defender la zona, la sentencia del juez Peñalver, que se apoya en una previa del conde Juan Portocarrero, ratifica la usurpación de términos materializada desde I463. Sin duda, el apoyo condal y la fuerza de la oligarquía, que mayoritaria o muy significativamente había defendido la causa isabelina, fueron factores determinantes. En cualquier caso, el citado juez dicta de modo sorprendente una sentencia en contra de los principios sobre restitución de términos de las Cortes de Toledo de I480. La extensión de la dehesa aumentó considerablemente y su nueva capacidad ganadera se situó muy por encima de la estimación establecida en el vaqueamiento de 1460.

Esta sentencia parece cerrar la lucha por este espacio anteriormente comunal. En el siglo XVI, se mantienen los conflictos por límites propiciados por las nuevas concesiones de rozas. La dehesa debió ampliarse también mediante compras. Las falsificaciones documentales no estuvieron ausentes. En todo caso, el espacio objeto de disputa no era comparable al usurpado entre I463-I495. La definitiva consolidación del poder real supuso un freno decisivo para realizar grandes apropiaciones.

La dehesa de Castilrubio no fue habitualmente aprovechada por sus propietarios, aunque en ella pastaron las vacas de Juan de Susilla y luego de su hijo Rodrigo Alonso de Susilla. Es probable que el primero tuviera una importante dedicación ganadera. En general, los propietarios cedieron en arriendo la dehesa a vecinos y mesteños. La explotación a pasto y labor sólo se documenta a principios de la segunda mitad del XV. A partir de entonces, al margen de la explotación agraria de ciertas rozas, se impone la explotación ganadera, que se vio favorecida por la 
subida del precio de las hierbas. No podemos olvidar los colmenares concedidos por la villa que se sitúan en los límites de la propia dehesa y que aprovechan la abundante vegetación que aún se sigue documentando a mediados del siglo XVI.

Llama la atención la importancia de las élites aldeanas locales. Habitualmente, vecinos de Mengabril, Aldea del Valle o Cristina arriendan la dehesa Castilrubio para sus vacas. Debemos añadir a ello, el control mayoritario por miembros de este grupo de la propiedad de la dehesa en la primera mitad del siglo XV. Supone un elemento de contraste en un tipo de propiedad prácticamente monopolizado por la oligarquía local y, en menor medida, por otros sectores nobiliarios y eclesiásticos. Sin duda, nos está indicando su temprana conformación, que debemos retrotraer a principios del XV como muy tarde y seguramente antes.

En síntesis, confluyen en la dehesa de Castilrubio las líneas más importantes del mundo rural castellano en la baja Edad Media: la ampliación del terrazgo agrario y el receso de la vegetación natural; la usurpación de términos, aspecto muy vinculado al fenómeno anterior y al poder de la oligarquía, en particular de la familia Susilla; el dinamismo de las élites aldeanas en cuanto propietarios de Castilrubio, desde principios del XV y hasta una fecha indeterminada, propietarios de ganado vacuno y arrendadores de pastos. Pero, sobre todo, la historia de Castilrubio es una historia de poder, que explica la usurpación de términos y su refrendo legal en contra de las directrices de una monarquía que no siempre consigue que sus postulados se materialicen de modo efectivo en el ámbito local. 


\section{BIBLIOGRAFÍA}

AsEnjo GonZÁLEZ, María (I984), «Labradores ricos: nacimiento de una oligarquía rural en la Segovia del s. XV», En la España Medieval, 4, pp. 63-85.

ANES, Gonzalo (1970), Las crisis agrarias en la España moderna, Madrid, Taurus.

BAVEL, J. P. van (2003), «Early Proto-Industrialization in the Low Countries? The Importance and Nature of Market-Oriented Non-Agricultural Activities on the Countryside in Flanders and Holland, c. I250-I570", Revue Belge de Philologie et d'Histoire, 8I/4, pp. II09-II65.

Berges SÁNchez, Juan Manuel (2009), Actividad y estructuras pecuarias en la comunidad de Albarracín (I284-I5I6), Tramacastilla, C. E. Comunidad de Albarracín.

Bernáldez, Andrés (I962), Memorias del reinado de los Reyes Católicos (edic. de Manuel Gómez-Moreno y Juan de Mata Carriazo), Madrid, Academia de la Historia.

CARmona Ruiz, Ma Antonia (1995), Usurpaciones de tierras y derechos comunales en Sevilla y su tierra durante el siglo XV. Madrid, Ministerio de Agricultura.

CARmona Ruiz, Ma Antonia (I999), «La apicultura sevillana a fines de la Edad Media», Estudios Agrosociales y Pesqueros, I85, pp. I3I-I54.

CArrasco Tezanos, Ángel (2006), La sociedad campesina en la sierra de Guadarrama a finales de la Edad Media, Madrid, A.C. Al-Mudayna.

CABrillana, Nicolás (I969), «Salamanca en el siglo XV: nobles y campesinos», Cuadernos de Historia. Anexos de la Revista Hispania, 3, pp. 255-295.

CASAdo Alonso, Hilario (1987), Señores, mercaderes y campesinos. La comarca de Burgos a fines de la Edad Media, Madrid, Junta de Castilla y León.

Clemente Ramos, Julián (200I), «La evolución del medio natural en Extremadura (II42I525)», en El medio natural en la España medieval. Actas del I Congreso sobre ecohistoria e historia medieval (pp. I5 - 56), Cáceres, Universidad de Extremadura.

Clemente Ramos, Julián (2002-3), «Valdetorres, de dehesa a aldea (I409-I5IO). Poblamiento, conflicto y poder en la tierra de Medellín», Studia Historica. Historia Medieval, 20-2I, pp. 47-72.

Clemente Ramos, Julian (2005), «El vaqueamiento de las dehesas de Medellín (I460)», Norba. Revista de Historia, I8, pp. I37-I46.

Clemente Ramos, Julián (2007), La tierra de Medellín (I234-c. I450). Dehesas, ganadería y oligarquía, Badajoz, Diputación de Badajoz.

Clemente Ramos, J. (20I0), «La tierra de Galisteo (c. I375-c. I425). Transformaciones del poblamiento y apropiaciones ilegales», Arqueología y Territorio Medieval, I7, pp. 3I- 46.

Clemente Ramos, J. (2012), «Ocupación del espacio y formas de explotación. Dehesas y adehesamiento en Extremadura (c. I250-c. I450)», en La historia peninsular en los espacios de frontera: Las «Extremaduras históricas» y la «Transierra» (siglos XI-XV), Cáceres- Murcia, Sociedad Española de Estudios Medievales, pp. 253-277.

Clemente Ramos, Julian (20I3), «El espacio pecuario en Medellín (I450-I550)», Anuario de Estudis Medievales, 43/2, pp. 505-54I.

CLEMENTE RAmos, Julián: «La ganadería en Medellín (I450-I550): propietarios y cabañas», Anuario de Estudios Medievales, 44/2 (2014), pp. 807-844.

CoOper, J. P. (I988), «En busca del capitalismo agrario», en El debate Brenner. Estructura de clases agraria y desarrollo económico en le Europa preindustrial, Barcelona, Crítica, I64- 229.

Cortes de los antiguos reinos de León y de Castilla, tomo IV (I882), Madrid, Academia de la Historia. 
Del Pino García, José Luis (I992), Extremadura en las luchas políticas del siglo XV, Badajoz, Diputación de Badajoz.

Diago Hernando, Máximo (I99I), «Los términos despoblados en las comunidades de villa y tierra del Sistema Ibérico castellano a finales de la Edad Media», Hispania. Revista Española de Historia, 51/2, pp. 467-515.

Díaz de Durana, José Ramón (I998), «El mundo rural guipuzcoano al final de la Edad Media: progreso agrícola, gestión y explotación de la tierra», En la España Medieval, 2I, pp. 69-96.

DyER, Cristopher (I99I), Niveles de vida en la Baja Edad Media. Cambios sociales en Inglaterra, c. I200-I520, Barcelona, Crítica.

Franco Silva, Alfonso (2002), «La Codosera: La repoblación de una villa fronteriza en tierras de Badajoz», en Estudios sobre D. Beltrán de la Cueva y el ducado de Alburquerque, Cáceres, Universidad de Extremadura, pp. I83-198.

García Garcimartín, Hugo Joaquín (2004), El valle del Alberche en la Baja Edad Media (siglos XII-XV), Ávila, Diputación de Ávila.

García Sanz, Francisco (I997), La Condesa de Medellín: Da Beatriz de Pacheco. Medellín, edic. personal.

GARCíA SANZ, Ángel (I994), «Explotación y renta en una dehesa salmantina durante el siglo XIX: Miguel Muñoz, I802-I895», en El medio rural español. Cultura, paisaje y naturaleza. Homenaje a don Angel Cabo Alonso, vol. I, Salamanca, Universidad de Salamanca, pp. 347-38o.

Gerbet, Ma Claude (I979), La noblesse dans le royaume de Castille. Étude sur ses structures sociales en Estrémadure (1454-I5I6), Paris, Université de Paris IV.

Goicolea Julián, Francisco Javier (I999), Haro: Una villa riojana del linaje Velasco a fines del Medievo, Logroño, Instituto de Estudios Riojanos.

Gomez-Menor, José Carlos (I985), «Una casa de labradores acomodados de la villa de Yepes en I505. Hacienda, ajuar y precios», Toletum, I7, pp. I94-I99.

GoNZÁlEZ ARCE, José Damián (I998), Apariencia y poder. La legislación suntuaria castellana en los siglos XIII-XV, Jaén, Universidad de Jaén.

JACQUART, Jean (I984), «Réflexions sur les notables ruraux. Le groupe des marchandslaboureurs en Île-de-France du XV siècle à la Révolution», en Congreso de historia rural. Siglos XV-XIX, Madrid, Casa de Velázquez - Editorial Complutense, pp. 645-658.

LADERO QUESADA, Miguel Ángel (2004), «La caballería y la población de Extremadura según los alardes de I502», Norba. Revista de Historia, I7, pp. I57-I86.

LóPEZ-SAlAZAR PÉREZ, Jerónimo (I986), Estructura agraria y sociedad rural en La Mancha (siglos XVI-XVII), Ciudad Real, Instituto de Estudios Manchegos.

López-Salazar Pérez, Jerónimo (I987), Mesta, pastos y conflictos en el Campo de Calatrava durante el siglo XVI, Madrid, CSIC.

Mazo Romero, Fernando (I977), El condado de Feria (1394-1505). Contribución al estudio de régimen señorializador en Badajoz. Badajoz, I. C. Pedro de Valencia.

Melón JimÉnez, Miguel Ángel; Rodríguez Grajera, Alfonso (I985); «Crecimiento demográfico y extensión de cultivos en Coria y su tierra durante el siglo XVI», Norba. Revista de Historia, 6, I7I-I74.

Molenat, Jean-Pierre (I997), Campagnes et monts de Tolede $d u X I^{e}$ au XV siécle, Madrid, Casa de Velázquez.

Monsalvo ANTón, José María: «Paisaje agrario, régimen de aprovechamientos y cambio de propiedad en una aldea de la tierra de Ávila durante el siglo XV. La creación del término redondo de Zapardiel de Serrezuela», Cuadernos Abulenses, I7/I (I992), pp. II-IIo.

Monsalvo AnTón, José María: «Usurpaciones de comunales. Conflicto social y disputa legal en Ávila y su tierra durante la baja Edad Media», Historia Agraria, 24/2 (200I), pp. 89-I22. 
Monsalvo Antón, José María: «La ordenación de los espacios agrícolas, pastoriles y forestales del territorio abulense durante la baja Edad Media», en Del SER Quijano, Gregorio (ed.), Historia de Ávila. IV. Edad Media (siglos XIV-XV). $2^{a}$ parte, Ávila, Institución Gran Duque de Alba, 2009, pp. 349-497.

MORICEAU, Jean-Marc (I994), Les fermiers de l'île-de-France. L'ascension d'un patronat agricole $\left(X V^{e} X V I I l^{e}\right.$ siècle), París, Fayard.

Pereira Iglesias, J. L. (I990), Cáceres y su tierra en el siglo XVI. Economía y sociedad, Cáceres, I. C. El Brocense.

Pereira Iglesias, José Luis (I998), «La trashumancia en zonas de invernadero: el ejemplo de la tierra de Cáceres», en Mesta, trashumancia y lana en la España moderna, Barcelona, Crítica, pp. 23I-258.

Pérez Bustamante, Rogelio; Calderón Ortega, José Manuel (I998); Enrique IV, I454-I474, Burgos, Editorial La Olmeda.

Puñal Fernández, Tomás (I998), «La ganadería lanar en Madrid y su tierra durante la Edad Media», Espacio, Tiempo y Forma. III. Historia Medieval, II, pp. 33I-38I.

Quesada Quesada, Tomás (I994), El paisaje rural de la campiña de Jaén en la Baja Edad Media según los libros de las dehesas, Jaén, Universidad de Jaén.

Rodríguez Blanco, Daniel (I985), La Orden de Santiago en Extremadura en la Baja Edad Media (siglos XIV y XV), Badajoz, Diputación de Badajoz.

SÁNCHEZ BENito, José María: «Aproximación al estudio de un sector económico en Castilla a fines de la Edad Media: la explotación colmenera», Hernán Cortés y su tiempo. Actas del Congreso Hernán Cortés y su tiempo. V Centenario (1485-I985), Guadalupe-CáceresMedellín], I985, vol. I, Mérida, I987,

SÁnchez Benito, José María: «Organización y explotación de la tierra de Huete (siglo XV)», Historia. Instituciones. Documentos, 26 (I999), 49I-546

SÁNCHEz Loro, Domingo (I983), Historias placentinas inéditas, Cáceres, I. C. El Brocense, vol. 2.

SÁNChez Rubio, Ma Ángeles (I993), El concejo de Trujillo y su alfoz en el tránsito de la Edad Media a la Edad Moderna, Cáceres, Universidad de Extremadura.

Segrelles Serrano, J. A. (I989), «La apicultura valenciana: un aprovechamiento agrario tradicional», Cuadernos de Geografía, 45, pp. 73-88.

SuÁrez Alvarez, Ma Jesús (I982), La villa de Talavera y su tierra en la Edad Media (I369-I504), Oviedo, Universidad de Oviedo.

SuÁREZ Fernández, Luis (I975), Nobleza y monarquía. Puntos de vista sobre la historia política castellana del siglo $X V$, Valladolid, Universidad de Valladolid. 


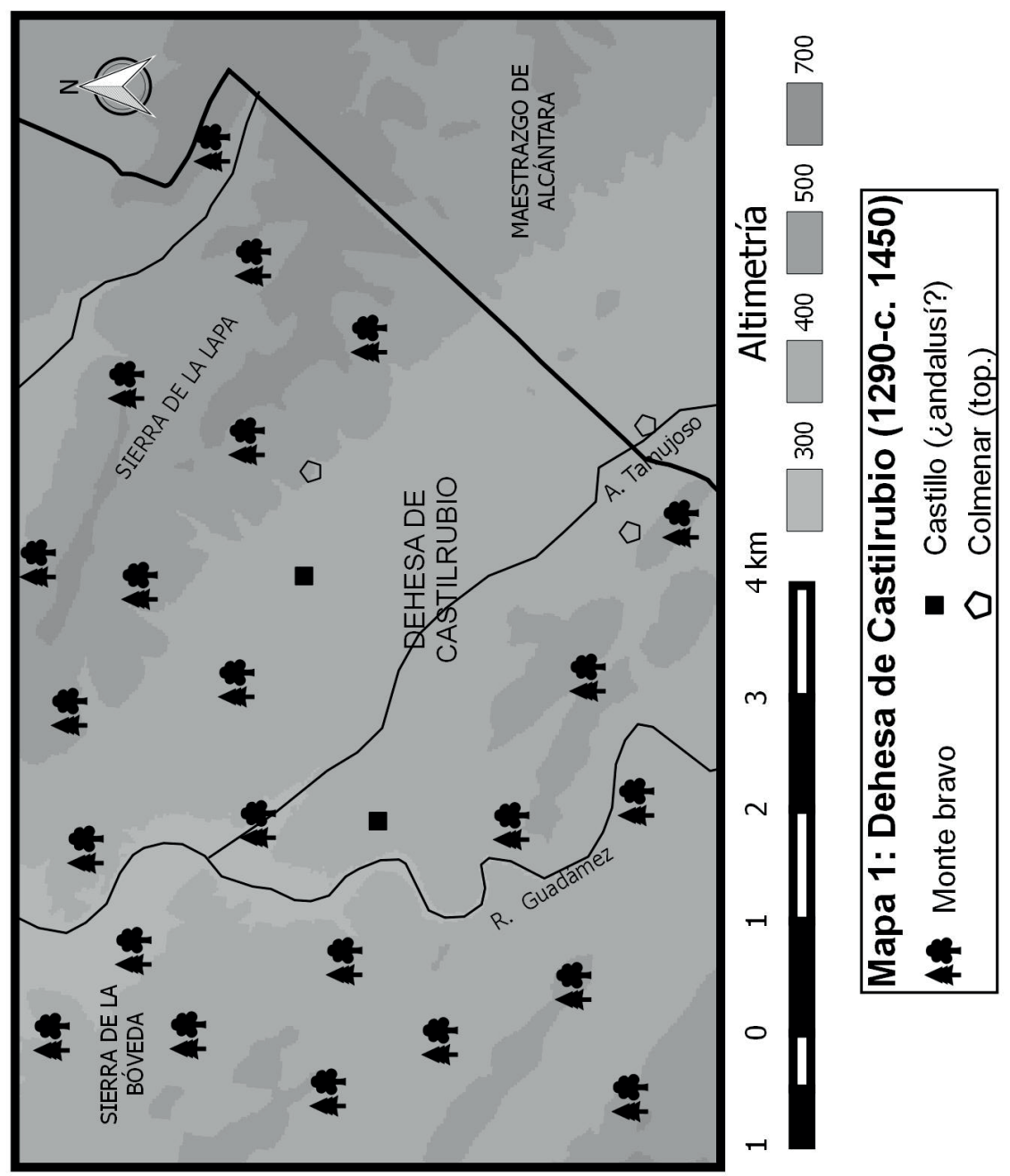




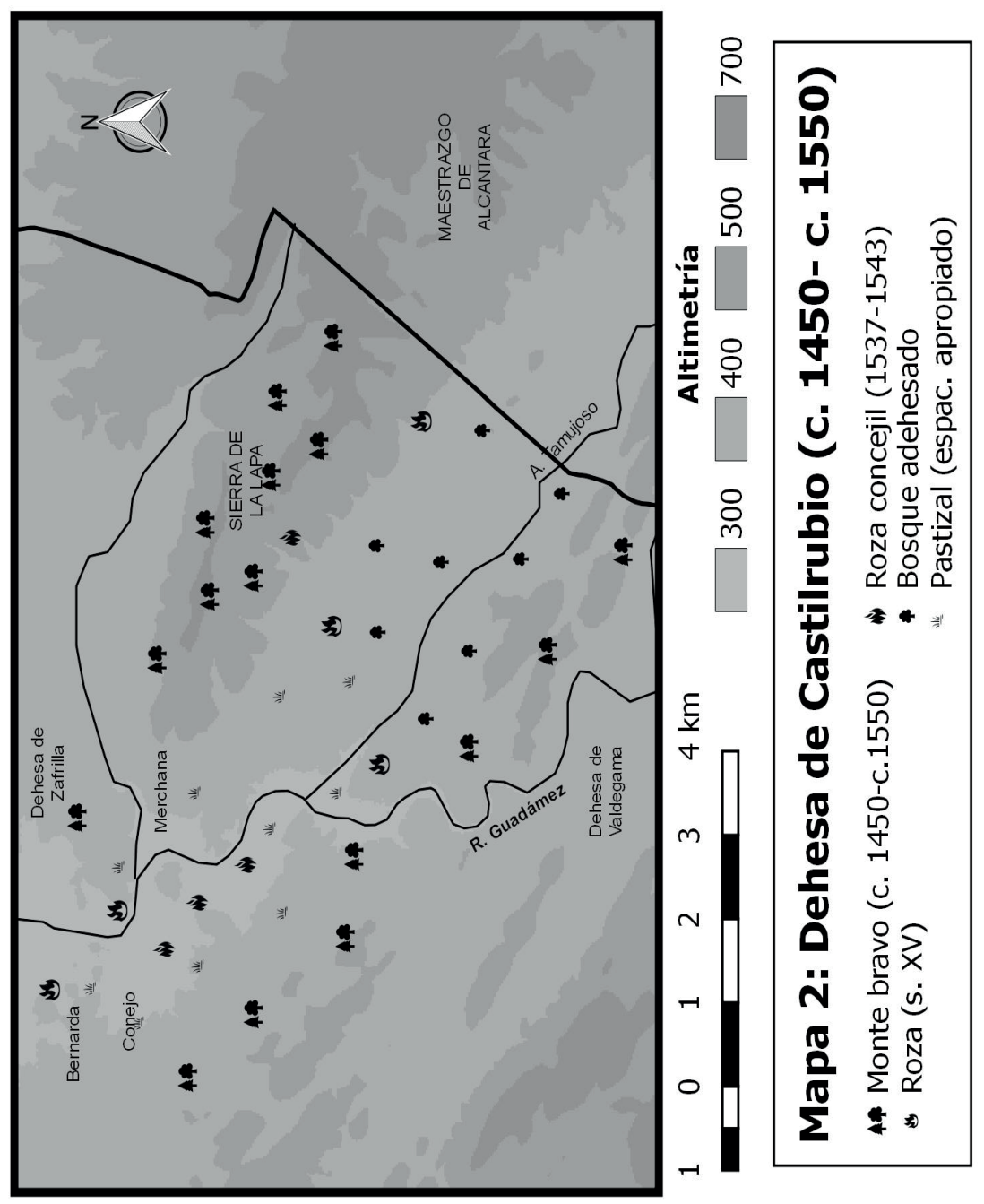



Calidad de Revistas

Científicas Españolas

FECYT|
AÑO 2019

ISSN: 0214-9745

E-ISSN 2340-1362

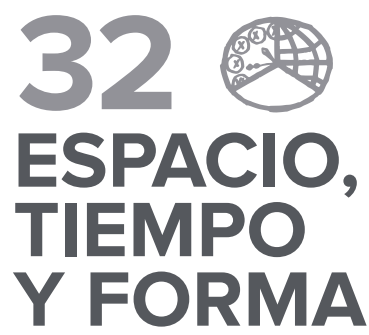

SERIE III HISTORIA MEDIEVAL

REVISTA DE LA FACULTAD DE GEOGRAFÍA E HISTORIA

\section{Artículos · Articles}

JoAquín Aparici Martí \& Concepción Villanueva Morte Deslindes y amojonamientos medievales en las serranías de Gúdar-Maestrazgo: un acercamiento al patrimonio rural y a la didáctica del territorio

\section{CARLOS BARQuero GoÑ}

Los hospitalarios y los monasterios en la Corona de Castilla durante los siglos XII y XIII

\section{Rocío BELLO GAY}

Representación política, oficios concejiles y acumulación económica en las aldeas abulenses en la Baja Edad Media: algunos apuntes acerca de la caracterización de las Ilamadas elites rurales (1474-1504)

105 Albert Cassanyes Roig Edad Media

La iglesia de Mallorca y la redención de cautivos en la Baja

133 Julián Clemente Ramos

Una dehesa por dentro: Castilrubio (1290-c. 1545). Paisaje, explotación y usurpación de términos

161 Francisco josé Díaz Marcilla

Las relaciones sociales dentro del Cancionero de Juan Alfonso de Baena (siglo XV). Redes y mentalidades

187 GUILLERMO FERnÁNDEZ ORTIZ

El archivo del monasterio cisterciense de Nuestra Señora de Belmonte (Asturias, España) en vísperas de la Reforma (1560)

\section{IVÁN GARCíA IZQUIERDO}

El linaje de Aza durante los siglos XIII y XIV: declive y resurgimiento

267 JAVIER LóPEz RÍder

Migraciones rurales en el paisaje meridional del Reino de Córdoba en el tránsito de la Edad Media a la Moderna

303 Jesús Rodríguez MoRAles \& DAVID GonzÁlez Agudo
Los caminos de la repoblación segoviana en la Transierra entre los siglos XIII y XV a partir del Privilegio de las Alberguerías de 1273

337 Jonatan Romero Pérez el siglo XIV
Estructuras militares y logísticas en la Corona de Castilla durante
379 VICENT ROYO PÉREZ

Árbitros y mediadores en el mundo rural valenciano durante la Baja Edad Media: Els Ports y El Maestrat (s. XIII-XIV)

Xosé M. SÁnchez SÁnchez

Aproximación al concejo de la ciudad de Santiago de Compostela y su configuración entre los siglos XIII-XV. Un poder urbano en el señorío episcopal

4.4.9 Fernando Serrano Larráyoz \& Manuel Francisco CARRILlo Rodríguez

Nueva perspectiva acerca de las enfermedades de Enrique IV de Castilla: el recetario del doctor Gómez García de Salamanca

\subsection{Néstor Vigil Montes}

«Tractados de pazes, aliança e concordia entre as duas coroas de Portugal e Inglaterra», un cartulario realizado a comienzos del siglo XV para consolidar el Tratado de Windsor entre los reinos de Inglaterra y Portugal (1386), la alianza permanente más prolongada de la historia

\section{Notas de Filología castellana medieval · Notes of Medieval Castilian Philology}

(9) 1 Francisco Abad Nebot

Notas bibliográfico-críticas de Filología castellana medieval

\section{Libros $\cdot$ Books}

515 Arsuaga Laborde, Diego, Pedro Fernández de Velasco, primer conde de Haro. Un estudio de la figura de un ricohombre en la Castilla del Cuatrocientos (CARLOS BARQUERO GOÑI)

517 BECEIRO PITA, Isabel (directora), La espiritualidad y la configuración de los reinos ibéricos (siglos XII-XV) (ENRIQUE Cantera Montenegro)

529 Galende Díaz, Juan Carlos, Ávila Seoane, Nicolás, El rodado regio hispánico: León y Castilla antes de la unificación (1157-1230) (MAURICIO HERRERO JIMÉNEZ)

533 IrIJOA Cortés, lago, Goicolea Julián, Francisco Javier, García FERNÁNDEZ, Ernesto (coords.), Mercaderes y financieros vascos y riojanos en Castilla y en Europa en el tránsito de la Edad Media a la Moderna (Ana MARÍA Rivera MEdina) 


\section{2 -}

\section{ESPACIO,}

\section{TIEMPO}

\section{Y FORMA}

UกED

SERIE III HISTORIA MEDIEVAL

REVISTA DE LA FACULTAD DE GEOGRAFÍA E HISTORIA

\section{Libros · Books}

537 LACARRA, José María, Alfonso el Batallador. Estudio preliminar de Fermín Miranda (PAULINA LóPEZ PITA)

541 Martín López, María Encarnación y CaVero Domínguez, Gregoria, Colección Documental del Monasterio de San Guillermo de Villabuena (1172-1527) (JOSÉ MIGUEL LóPEZ VILLALBA)

545 Martín Prieto, Pablo, Las Cruzadas (Margarita Cantera MONTENEGRO)

547 Rı, Alice, Legal Practice and the Written World in the Early Middle Ages. Frankish Formulae, c. 500-1000 (AlEJANDRO PABLO BAÑón PARDO)

551 RoYo PÉrez, Vicent, Les arrels històriques de la comarca dels Ports. Societat, poder i identitat en una terra de frontera durant la Baixa Edat Mitjana (JULIÁN DONADO VARA)

555 SANTIAgo Fernández, Javier de, Política monetariay moneda en el reinado de Carlos II (José Miguel López VILLALBA)

559 Santiago Fernández, Javier de y Francisco Olmos, José María. de, Corpus Inscriptionum Hispaniae Mediaevalium. Guadalajara (11121499) (José Miguel López VILLALBA)

563 Solórzano Telechea, Jesús A. y Sousa Melo, Arnaldo (eds.), ZALACAIN) Trabajar en la ciudad medieval europea (ROBERTO J. GONZÁLEZ

567 Solórzano Telechea, J.A., Haemers, J., Czaja, R. (eds.), Exclusión y disciplina social en la ciudad medieval europea (MARÍA ÁlvareZ FernánDEZ)

571 TRANChant, Mathias, Les ports maritimes de la France atlantiMARTÍN PÉREZ) que $\left(X l^{e}-X V^{e}\right.$ siècle). Volume I: Tableau géohistorique (FERNANDO 